\title{
The Relation of Meteorological Elements with AOD for Building Energy Consumption
}

\author{
Hong Soo Lim and Gon Kim \\ Department of Architectural Engineering, Kyung Hee University, Yongin 446-701, Republic of Korea \\ Correspondence should be addressed to Gon Kim; gonkim@khu.ac.kr
}

Received 12 July 2017; Accepted 11 October 2017; Published 10 January 2018

Academic Editor: Gabriele Curci

Copyright ( 2018 Hong Soo Lim and Gon Kim. This is an open access article distributed under the Creative Commons Attribution License, which permits unrestricted use, distribution, and reproduction in any medium, provided the original work is properly cited.

\begin{abstract}
This study presents statistical relationships between various meteorological elements in Seoul city. It also discusses the vitality of the obtained relationship on the modelling of building energy consumption. The data utilized in statistical evaluations was obtained from the archives of the Korean Meteorological Agency (KMA) for a period of four years. Another set of data was derived from stateof-the-art equations. The used elements aside from aerosols are used for analysis in building energy simulations. For each weather element in the study, frequency and a monthly average are presented. Furthermore, statistical correlations are presented: solar radiation and temperature, solar radiation and sky cover, and solar radiation and aerosol optical depth (AOD). The results indicate that the common assumption of a direct relationship between temperature and solar radiation is rather incorrect. In addition, whereas high solar altitudes are usually associated with high levels of solar radiation, the obtained results indicate a relatively weak relationship between the two variables $\left(R^{2}=0.463\right)$. The obtained results are proof that the effect of meteorological elements on, say, a building is not a single direct effect from a single variable but rather a combination of relationships between variables, which then produce a single effect.
\end{abstract}

\section{Introduction}

Buildings consume a significant amount of energy. In the US alone, it is estimated that the building sector consumes about $40 \%$ of the total energy produced [1]. Similar numbers are noticed around the world. Given the nature of the energy sources currently being utilized and the effect they have on the environment, it is important that endeavors to reduce energy consumption in all sectors are taken seriously.

Architects and scholars have made recognizable effort in reducing building energy consumption. Numerous passive strategies to reduce the dependency of buildings on the mainstream energy are being used today. Good examples for such practices include solar shading and cross ventilation. These kinds of practices have contributed massive strides in the reduction of building energy consumption. However, such passive strategies become even more helpful when coupled with the ability to predict the behavior of a building prior to actual construction; for instance, knowledge regarding the thermal behavior of a given space during the design stage might be helpful in determination of which solar control to use or during the sizing of HVAC systems. Fortunately, a number of buildings simulations tools have become very common recently. Through these tools, a lot of information in regard to the behavior and performance of a space can be deduced in the design stages. These building simulations tools rely on developed algorithms, weather, and climatic data as well as other user-specified data such as occupant behavior data and the thermal properties of building elements to predict the behavior of a given building, for instance, a building's total heating or cooling load.

However, just like most software-based programs, the accuracy of predicted results from building simulation tools is highly dependent on the input data, especially weather data. In the past, the weather input data only considered basic weather factors such as solar radiation, humidity, and wind speed. However, recently, almost all building simulation tools allow for the input of a much more detailed weather data file that includes complicated elements such as ground reflectance and turbidity levels. Even though current building 
simulation tools consider a wide set of weather elements, many more climatic factors need to be considered to improve the accuracy of the simulated results. In addition, scientific studies focusing on the relation of climatic conditions in regard to building energy consumption are rather insufficient. Therefore, this study, through a statistical approach, discusses the relationship between several weather elements for the climate of Seoul city. The variables discussed can be easily summarized in three basic categories: weather data, solar radiation, and aerosols. Weather data include drybulb temperature dew-point temperatures, relative humidity, atmospheric station pressure, wind speed, wind direction, total sky cover, visibility, and precipitable water. Solar radiation includes extraterrestrial horizontal radiation, extraterrestrial direct radiation, horizontal infrared radiation, global horizontal radiation, direct normal radiation, and diffuse radiation. Aerosols include $\mathrm{SO}_{2}(\mathrm{ppm}), \mathrm{PM} 10\left(\mu \mathrm{g} / \mathrm{m}^{3}\right), \mathrm{O}_{3}$ (ppm), $\mathrm{NO}_{2}$ (ppm), $\mathrm{CO}$ (ppm), and AOD (aerosol optical depth). The results obtained in the current study would be of significant importance to building simulation tool developers who wish to understand the relationship between various meteorological elements and their effect on building energy modelling.

\section{Literature Review}

\subsection{Interrelationship between Solar Radiation and Architecture}

2.1.1. Extraterrestrial Solar Radiation. The radiation emitted by the sun to the outer space is of a consistent attenuation unlike that emitted to the earth's atmosphere. There are diverse methods used in calculating solar radiation. Some of these methods are based on developed theories and concepts, while others are based on actual data obtained from satellites. For this study, an equation based methodology is adopted in assessing the relationship between variables as well as evaluating energy consumption. This is because the data required by the current study is unavailable in a real-time form.

Electromagnetic energy remains constant as it passes through the universal space and reaches the earth. This is the reason why solar radiation reaching the outer space carries the same energy and wavelength as it had when leaving the surface of the sun. However, the intensity of such a radiation decreases as it is largely affected by the distance where it moves further away from the sun. Extraterrestrial radiation has constant data for a year as there are no many obstacles such as those present in the earth's atmosphere (Figure 1). As such, extraterrestrial radiation can be determined using (1)-(4). Equation (2) was developed by Spencer in 1971. It considers a solar constant and dates in its calculations. Equations (3) and (4) were developed by Iqbal in 1983. It follows a methodology that calculates extraterrestrial radiation by solar constant.

Solar constant $\left(G_{\mathrm{sc}}\right)$ refers to the energy from the sun per unit time reaching a unit area of a surface perpendicular to the direction of propagation of the radiation at mean earth-sun distance outside the atmosphere (see (1)). The solar constant $\left(G_{\mathrm{sc}}\right)$ is a critical factor in calculating extraterrestrial radiation and the current study adopts the solar constant value suggested by the World Radiation Center (WRC). The WRC suggests a value of $1367 \mathrm{~W} / \mathrm{m}^{2}$, with an uncertainty of the order $1 \%$ [3].

Assuming there is a sphere that covers the sun completely, diameter between the earth and the sun would have an average distance of $1.5 \times 10^{11} \mathrm{~m}$. The distance from the sun increases as radiant intensity decreases following the inverse square law. The intensity of solar energy from an incoming light that falls on a perpendicular plane can be derived from total solar radiation and the area of the imagined sphere. This radiation energy can then be used to calculate the solar constant value which is adduced by the World Radiation Center (WRC) as shown by (1) [4]

$$
\begin{aligned}
& \frac{3.865 \times 10^{26} \mathrm{~W}}{4 \pi\left(1.5 \times 10^{11} \mathrm{~m}\right)^{2}}=1367 \mathrm{~W} / \mathrm{m}^{2} \\
& \mathrm{ER}=G_{\mathrm{sc}}\left(1+\frac{0.033 \cos 360 n}{365}\right)
\end{aligned}
$$$$
\text { made by Spencer (1971), }
$$

$$
\begin{aligned}
\mathrm{ER} & =G_{\mathrm{sc}}(1.000110+0.034221 \cos B+0.001280 \sin B \\
& +0.000719 \cos 2 B+0.000077 \sin 2 B)
\end{aligned}
$$

made by Iqbal (1983),

$$
B=\frac{(n-1) 360}{365}
$$

The extraterrestrial radiation utilized in the current study is based on a methodology developed through the application of Iqbal equations. As indicated here, $96.3 \%$ of solar irradiance falls between $200 \sim 2500 \mathrm{~nm}$. It is worth emphasizing that the energy from the sun, is what is perceived as heat and light here on earth. Solar or short-wave radiation is radiation originating from the sun, in the wavelength range of 0.3 to $3 \mu \mathrm{m}$. It includes both beam and diffuse components. On the other hand, long-wave radiation is radiation originating from sources at temperatures near ordinary ambient temperatures and thus substantially all at wavelengths greater than $3 \mu \mathrm{m}$. Long-wave radiation is emitted by the atmosphere, by a collector, or by any other body at ordinary temperatures [5].

The region with the strongest intensity has a maximum wavelength ranging from 400 nanometers to 600 nanometers. It has a major influence on the ozone, water existing in the atmosphere, $\mathrm{CO}_{2}$, and a region called the daylighting zone by aerosols (380-780 nanometers) [6].

In order to convert the outer space sunlight into extraterrestrial horizontal radiation (EHR), the equation below is used. Equation (7) is also used to calculate the ratio of extraterrestrial horizontal radiation (EHR) to Global Horizontal Radiation (GHR). At any point in time, the solar radiation incident on a horizontal plane outside of the atmosphere is the normal incident solar radiation as given by

$$
\mathrm{EHR}=G_{\mathrm{sc}}\left(1+0.033 \cos \frac{360 n}{365}\right) \cos \theta z
$$




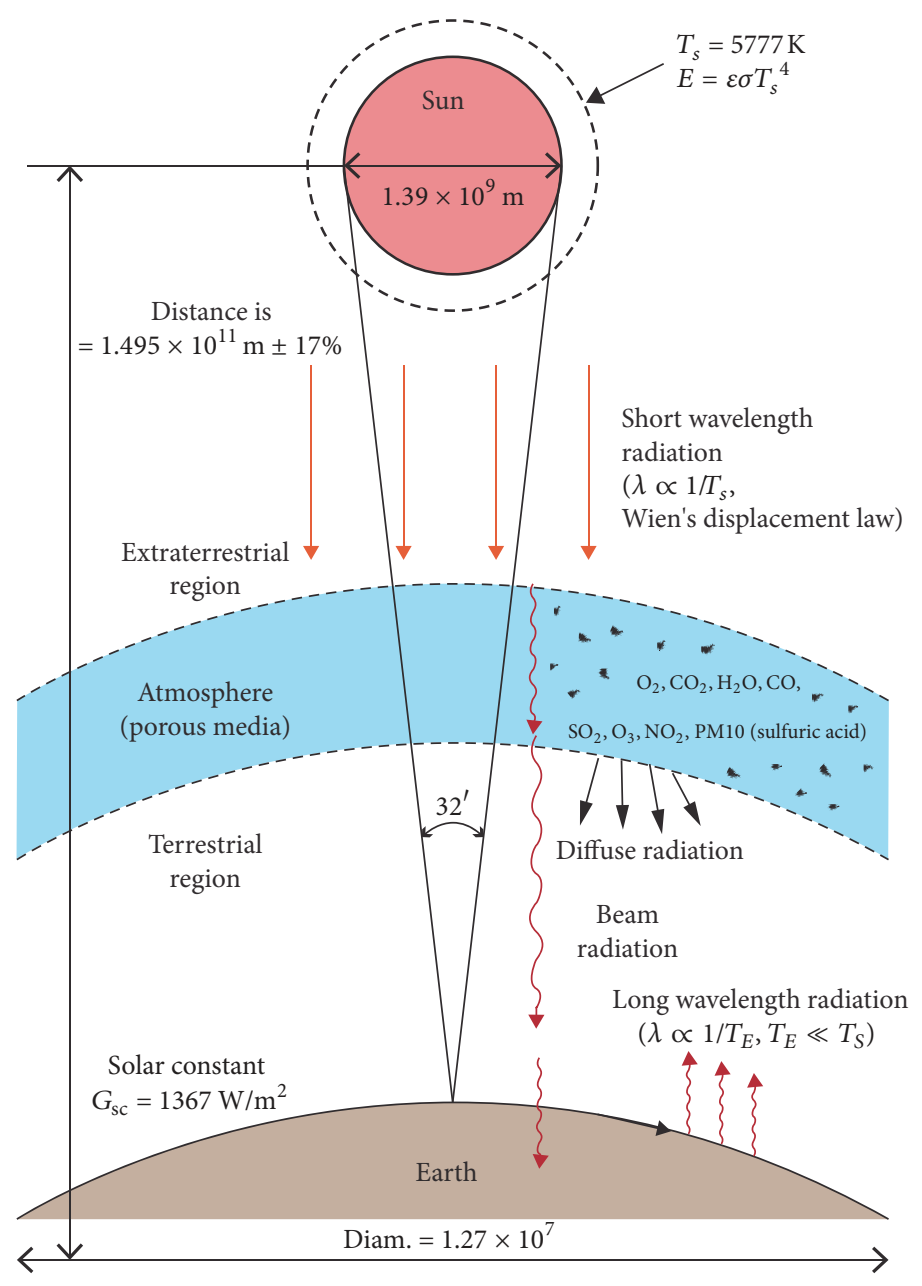

FIGURE 1: Behavior of solar radiation within the extraterrestrial and terrestrial regions.

$$
\begin{array}{r}
\mathrm{EHR}=G_{\mathrm{sc}}\left(1+0.033 \cos \frac{360 n}{365}\right) \\
\cdot(\cos \Phi \cos \delta \cos \omega+\sin \Phi \sin \delta)
\end{array}
$$

(see [3]), where $G_{\text {sc }}$ (solar constant) is a measurement of flux density per unit area that would be incident on a plane perpendicular to the rays and $n$ is the day of the year. $\Phi$ (latitude) is the angular location north or south of the equator, north positive; $-90^{\circ} \leq \Phi \leq 90^{\circ}, \delta$ (declination) is the angular position of the sun at solar noon (i.e., when the sun is on the local meridian) with respect to the plane of the equator, north positive; $-23.45^{\circ} \leq \Phi \leq 23.45^{\circ}, \theta_{z}$ (zenith angle) is the angle between the vertical and the line to the sun, that is, the angle of incidence of beam radiation on a horizontal surface, and $\omega$ (sunset hour angle) is the hour angle at either sunrise (when negative value is taken) or sunset (when positive value is taken).

Equation (2) (ER) multiplied by $\cos \theta_{z}$ (zenith angle) produces extraterrestrial horizontal radiation and is referred to as (5). This means that (5) can be represented by (6) using the latitude, declination, and sunset hour angle instead of the zenith angle.

$$
\frac{\mathrm{GHR}}{\mathrm{EHR}}=\frac{\text { Global Horizontal Radiation }}{\text { Extraterrestrial Horizontal Radiation }} \times 100 \text {. }
$$

In order to calculate how much sunlight attenuation is brought upon by the atmosphere, the current study utilized the GHR/EHR ratio, which is the ratio of extraterrestrial horizontal radiation to terrestrial radiation (global horizontal radiation). To obtain the ratio, the values of GHR and EHR are first determined. The EHR values are computed by (5). This is because the solar radiation penetrates the outer space without coming in touch with the atmosphere and thus is unaffected by the atmospheric medium. As for the GHR, which indicates the amount of radiation coming to the terrestrial surface through the atmosphere, the study adopted hourly meteorological data collected by the Korea Meteorological Administration (KMA). GHR can also be defined as the sum of direct radiation and diffuse radiation. As such, GHR values are largely affected by the distribution percentage of the two elements (direct and diffuse radiation). 


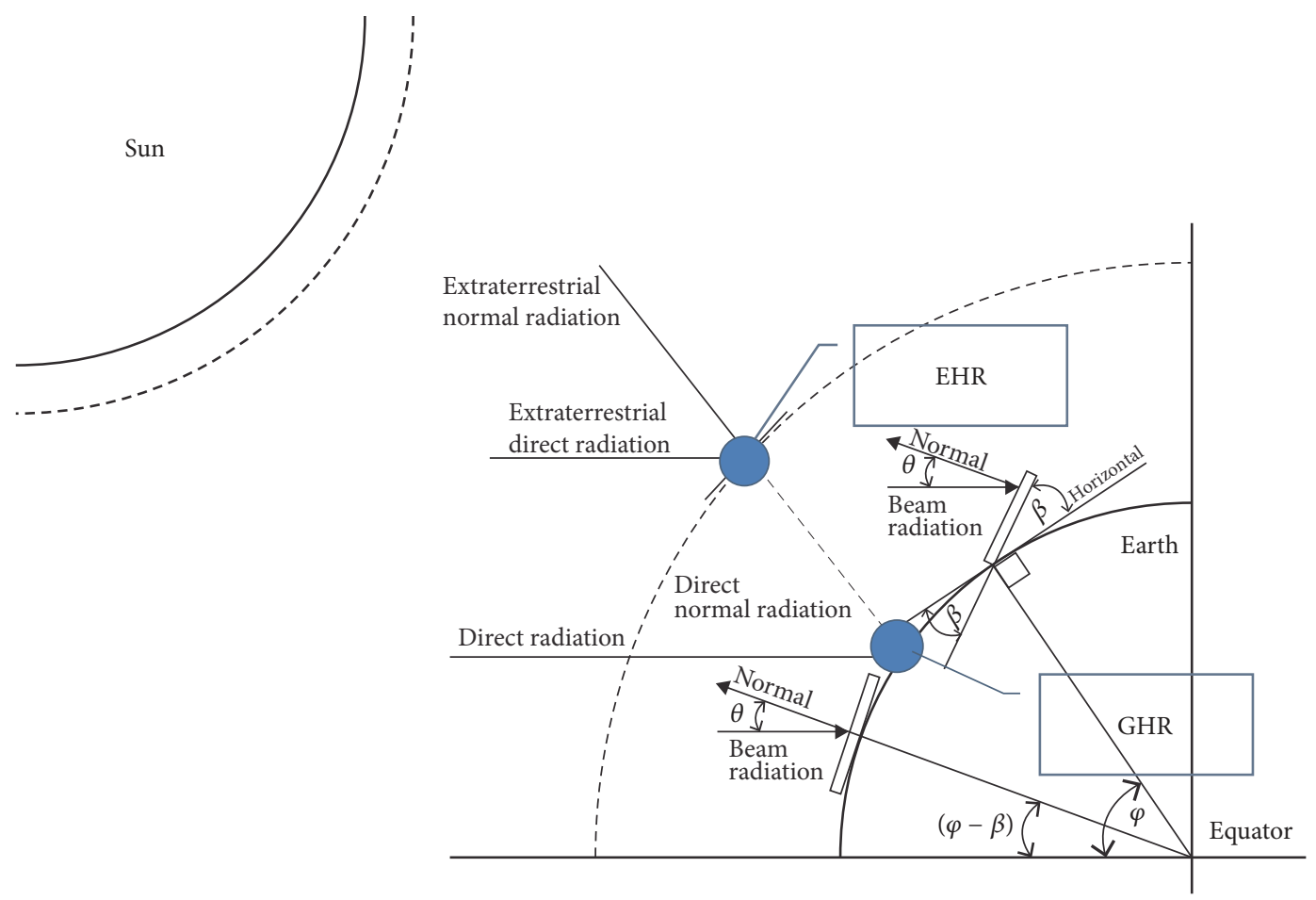

FIGURE 2: Concept behind the GHR/EHR equation.

The GHR/EHR ratio determined by (7) is calculated as a percentage and is largely dependent on the distance of transmission as well as the atmospheric conditions. The ratio is used to indicate the influx of radiation in the terrestrial surface and within buildings so as to help in the evaluation of the building thermal performance or brightness of the light reaching the inside of a building. Figure 2 explains the concept behind the GHR/EHR equation.

Figures 3 and 4 show the way the earth releases solar energy that it gains. The figure also shows that the amount of radiation that the earth gains is different from the amount that is reradiated and explain the data using percent scales. As indicated in the figure, when $114 \%$ of the energy is reradiated into the atmosphere, only $18 \%$ manages to escape into the outer atmosphere. This means that $96 \%$ of reradiated solar energy is absorbed by the atmosphere.

2.1.2. Direct and Diffuse Solar Radiation. Solar energy which is the main source of energy on earth is divided into two portions: direct and diffuse sunlight by the time it hits the earth. The proportion of these two elements (diffuse and direct sunlight) that the sun's radiation carries affects the behavior of buildings in regard to building thermal loads

When the proportion of direct sunlight is large, there is an increase in the amount of long wavelength infrared reaching the building. This long wavelength infrared that is known as thermal infrared raises the cooling load as a result of the increased indoor heat gain. As such, energy simulation computer software that is used to calculate thermal loads through the analysis of solar radiation usually separates the global horizontal radiation into two entities, beam radiation and diffuse radiation, before the analysis is conducted. The EnergyPlus software used in the current study behaves in such a way as well.

The separating method of direct and diffuse radiation presented in the EnergyPlus manual [7] is the same method presented by ASHRAE. As in (8), extraterrestrial normal irradiance is divided into beam normal radiance and diffuse horizontal radiance by considering air mass and aerosol optical depth. The air mass changes depending on the solar altitude as indicated by (9). Consequently, the air mass is used as a variable of exponential function.

In regard to the aerosol optical depth in (8), the final value is affected by other elements except for air mass. As a result, $E_{0}$ is calculated by (5) and $E_{\mathrm{b}}$ and $E_{\mathrm{d}}$ calculated by the exponential function are inversely proportional to the aerosol optical depth and air mass.

As such, the current study was conducted under the assumption that aerosol optical depth is able to affect energy consumption in buildings as it has an effect on the solar radiation reaching the building

$$
\begin{gathered}
E_{\mathrm{b}}=E_{0} \exp \left[-\tau_{\mathrm{b}} m^{\mathrm{ab}}\right] \\
\mathrm{ab}=1.219-0.043 \tau_{\mathrm{b}}-0.151 \tau_{\mathrm{d}}-0.204 \tau_{\mathrm{b}} \tau_{\mathrm{d}} \\
E_{\mathrm{d}}=E_{0} \exp \left[-\tau_{\mathrm{d}} m^{\mathrm{ad}}\right] \\
\mathrm{ad}=0.202-0.852 \tau_{\mathrm{b}}-0.007 \tau_{\mathrm{d}}-0.357 \tau_{\mathrm{b}} \tau_{\mathrm{d}}
\end{gathered}
$$

(see [8]), where $E_{\mathrm{b}}$ is beam normal irradiance (measured perpendicularly to rays of the sun), $E_{\mathrm{d}}$ is diffuse horizontal 


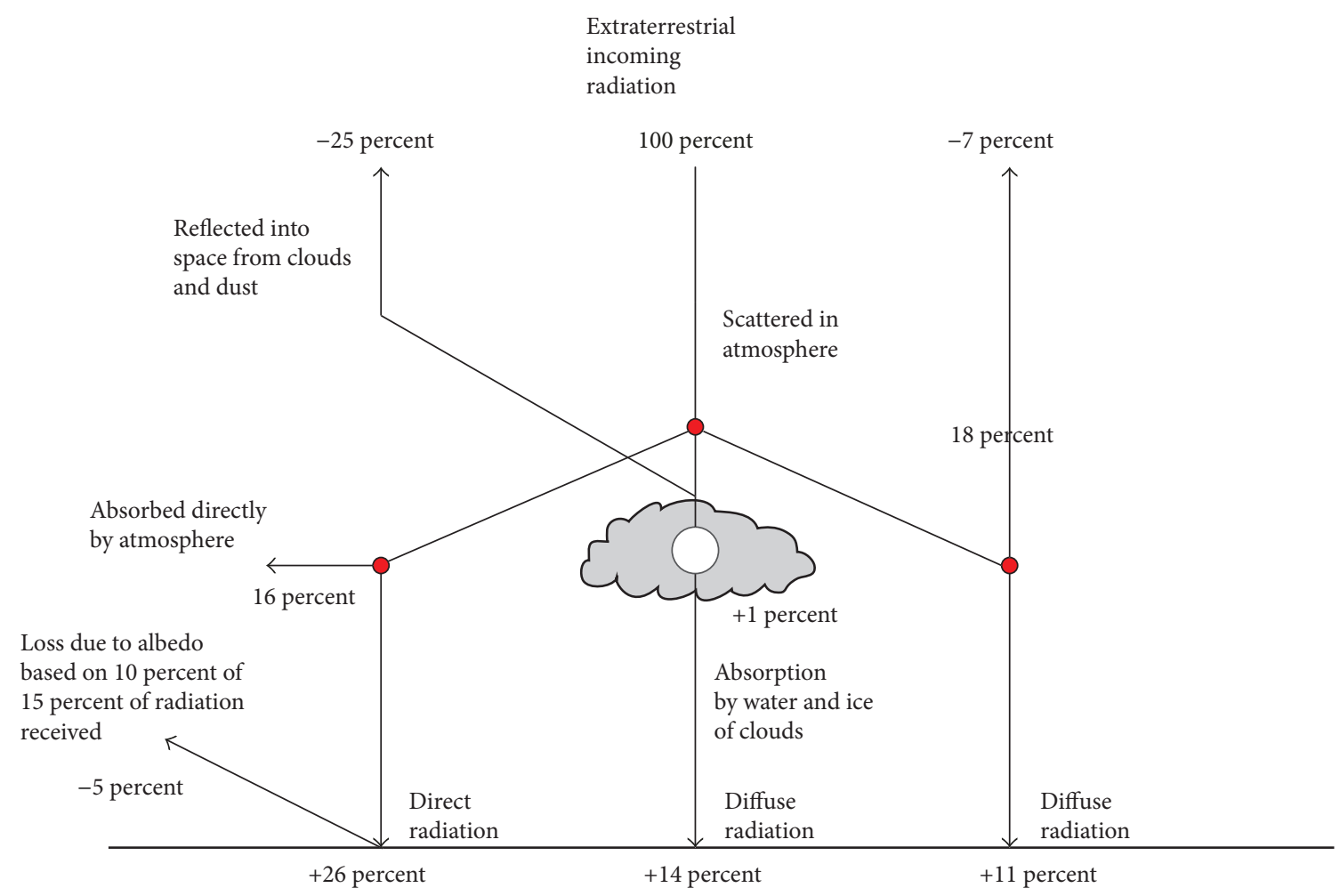

FIGURE 3: The ratio of absorption of solar energy by atmospheric elements (borrowed from buildings, climate, and energy by MARKUS) [2].

irradiance (measured on horizontal surface), $E_{0}$ is extraterrestrial normal irradiance, $\mathrm{ab}$ and ad are beam and diffuse air mass exponents (empirical relationships)

$$
m=\text { air mass: } \frac{1}{\left[\sin \beta+0.50572(6.07995+\beta)^{-1.6364}\right]}
$$

(made by Kasten and Young 1989)

(see [8]), $\tau_{\mathrm{b}}$ and $\tau_{\mathrm{d}}$ are beam and diffuse optical depths $\left(\tau_{\mathrm{b}}\right.$ and $\tau_{\mathrm{d}}$ are more correctly termed "pseudo" optical depths, because optical depth is usually employed when the air mass coefficient is unity; "optical depth" is used here for convenience), and $\beta$ is the angle between the line deriving from the sun and the horizontal plane. The values of $\beta$ range from 0 to 90 degrees, 0 degrees when the sun is positioned at the horizon, and 90 when the sun is at the zenith.

The air mass has an effect on the path taken by the solar beam from the moment it passes through the atmosphere to the moment it hits the earth. It is easy to see that $m=0$ for the extraterrestrial space or for an earth lacking an atmosphere [9].

Values of $\tau_{\mathrm{b}}$ and $\tau_{\mathrm{d}}$ depend on the location and change variably according to the time over the year. They form the link between solar radiation and other local conditions such as elevation and aerosols. The ASHRAE research project RP1453 (Thevenard 2009) was used to determine the average values of $\tau_{\mathrm{b}}$ and $\tau_{\mathrm{d}}$. The values were recorded for the 21st day of every month for all locations in the tables of climatic design conditions. For the other days of the year, average values of $\tau_{\mathrm{b}}$ and $\tau_{\mathrm{d}}$ can be found by interpolation [10].

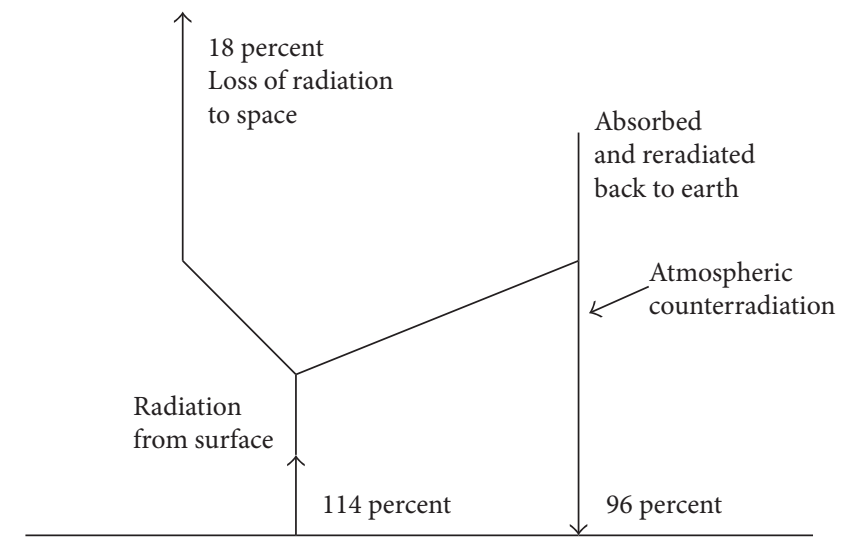

FIGURE 4: The ratio of reradiation of solar energy by atmospheric elements (borrowed from buildings, climate, and energy by MARKUS) [2].

\subsection{Interrelationship between Solar Radiation and Architecture}

2.2.1. Definition of Aerosol Optical Depth. Aerosols are very small particles of gas and other tiny particles that float in the atmosphere. The exact size of aerosols ranges from a fraction of a micrometer to a few hundred micrometers. Aerosols exist naturally. Also, their existence has been linked to anthropogenic sources such as volcanoes, dust, bacteria, and dust. Aerosols have a huge impact on the weather and climate that we experience here on earth as they are able to 


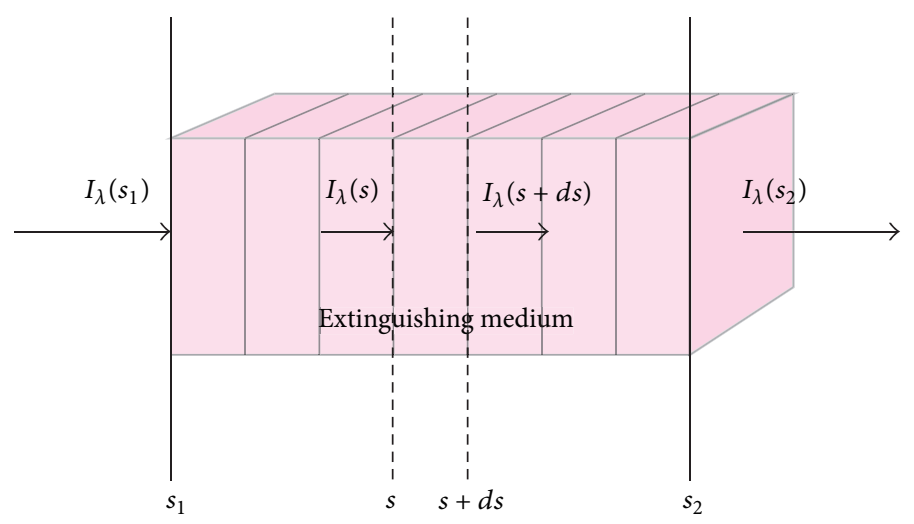

FIGURE 5: Change in solar radiation over an infinitesimal path $d s$ within a medium.

affect the amount of sunlight reaching the earth and thus the ability of aerosols to block the amount of sunlight reaching the earth is measured in terms of aerosol optical depth (AOD) or aerosol optical thickness (AOT). As the AOD at a given wavelength increases, the amount sunlight reaching the earth's surface decreases. Such information is critical for determining the availability of aerosols in the atmosphere as well as their size and distribution [11]. The concept of optical depth used in this study is described by adopting beer's law, and the percentage of solar radiation transmittance achieved through the absorption and the scattering of solar radiation could decrease depending on the condition of the earth's atmosphere as illustrated by (17). The coefficient of extinction denoted by the symbol $\left(\beta_{e}\right)$ is obtained through the sum of the absorption coefficient denoted by the symbol $\left(\beta_{a}\right)$ and the scattering coefficient denoted by the symbol $\left(\beta_{s}\right)$

In this section, we recall beer law of optical depth from " $a$ first course in atmospheric radiation" by Petty, Grant William

Beer's law of optical depth is represented by

$$
\beta_{e}=\beta_{a}+\beta_{s} .
$$

The absorption coefficient $\left(\beta_{a}\right)$ describes the amount of power attenuation that reaches a unit distance in a second. The relationship between the absorption coefficient $\left(\beta_{a}\right), n_{i}$, and wavelength $(\lambda)$ is represented by

$$
\beta_{a}=\frac{4 \pi n_{i}}{\lambda}
$$

In a medium of a uniform nature, an initial intensity denoted by $I_{0}$ the symbol at a position $x=0$ and which increases in the $x$-direction is described by

$$
\begin{aligned}
I_{\lambda}(x) & =I_{\lambda, 0} e^{-\beta_{a^{x}}} \\
\frac{I_{\lambda}(x)}{I_{\lambda, o}} & =e^{-\beta_{a^{x}}}=t_{\lambda}(x) \quad \text { transmittance function, }
\end{aligned}
$$

where $t$ is the transmittance: the amount of solar radiation that remains after travelling a certain distance $x$

Transmittance ranges from near zero to one. Given that the solar absorption coefficient is constant from points $s_{1}$ to $s_{2}$ then

$$
\tau=\beta_{e}\left(s_{2}-s_{1}\right) \quad \text { Optical depth. }
$$

The transmittance of radiation integrated over an optical path, $\tau \ll 1$, is calculated by

$$
t=\exp (-\tau) \approx 1-\tau\left(s_{1}, s_{2}\right)=1-\beta_{e}\left(s_{2}-s_{1}\right) .
$$

In a case where a medium remains intact (albedo $=0$ ), the remainder of the radiation that is not transmitted during the journey is absorbed. The path absorbance is then given by

$$
\begin{aligned}
& a=1-t, \\
& t=\frac{I}{I_{0}}=e^{-\tau} .
\end{aligned}
$$

If $I_{0}$ and $I$ represent the intensity of original light and the intensity of transmitted light, respectively, then the value of $t$ obtained by (14) on absorption coefficient represents "transmittance," while $\tau$ from (13) represents optical depth due to attenuation and light scattering. The amount of transmittance is $60 \%$ if $\tau$ value is 0.5 and $8 \%$ when the value of $\tau$ is 2.5. There is need to integrate Beer's law for an entire path through the atmosphere while considering the changes in $\beta_{e}$ as the location and the direction change. The integral quantity is the optical depth or optical thickness (when measured vertically in the atmosphere) or the optical path. It can have any positive value.

Figure 5 explains the attenuation by dividing the atmosphere into small pieces and using integral calculus on each section as (16). The calculated value $(\tau)$ is optical depth and the transmittance value $(t)$ could be determined using the exponential function (see (17)). Therefore, the calculated optical depth means attenuation coefficient with no scale. Figure 6 shows that function explaining the concept of optical depth

$$
\begin{aligned}
I_{\lambda}\left(s_{2}\right) & =I_{\lambda}\left(s_{1}\right) \exp \left[-\int_{s_{1}}^{s_{2}} \beta_{e}(s) d s\right], \\
t\left(s_{1}, s_{2}\right) & =e^{-\tau\left(s_{1}, s_{2}\right)} \\
\tau & =\beta_{e}\left(s_{2}-s_{1}\right), \\
\tau\left(s_{1}, s_{N}\right) & =\tau\left(s_{1}, s_{2}\right)+\tau\left(s_{2}, s_{3}\right)+\cdots+\tau\left(s_{N-1}, s_{N}\right), \\
t\left(s_{1}, s_{N}\right) & =t\left(s_{1}, s_{2}\right) \times t\left(s_{2}, s_{3}\right) \times \cdots \times t\left(s_{N-1}, s_{N}\right) .
\end{aligned}
$$




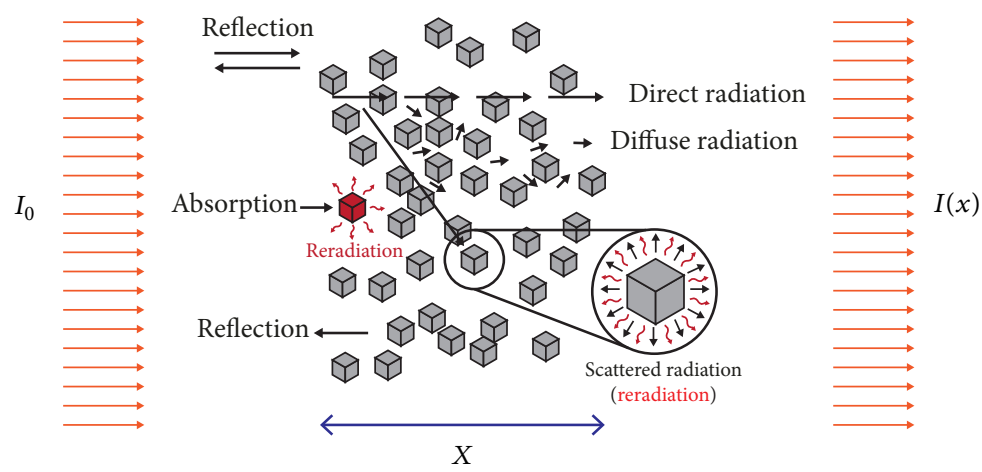

FIGURE 6: Function explaining the concept of optical depth.

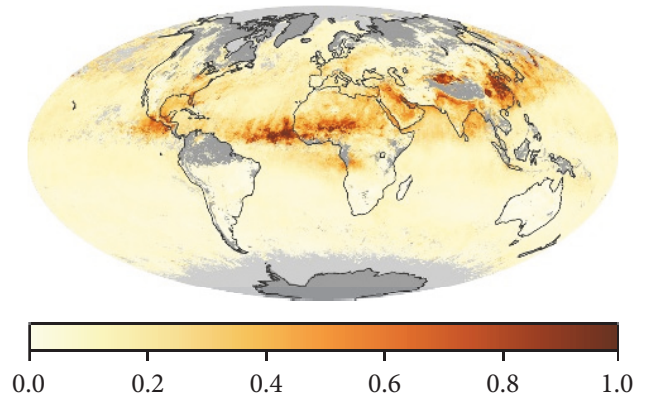

FIgURE 7: Global map of aerosol optical depth distribution. Available at https://earthobservatory.nasa.gov.

2.2.2. Measurement for Aerosol Optical Depth. Generally, AOD is obtained by (21). Optical depth can be determined using three methods: MODIS, MATCH, and AERONET

$$
\mathrm{AOD}_{\lambda}=B \cdot \lambda^{-\alpha}
$$

where " $\mathrm{AOD}_{\lambda}$ " is a representation of the aerosol optical depth at a given wavelength " $\lambda$." Three categories of data regarding aerosols are utilized: (a) MODIS which is obtained from space borne measurements using satellite pictures obtained through NASA homepage such as Figure 7, (b) chemical model for MATCH, and (c) aerosol optical depth data obtained through the MATCH and MODIS methods which were then compared with data obtained from actual ground sites. Most of this data was obtained through the AERONET network. For this particular study, data from 196 sites accumulated over a period of 3 years were used for a given month $[12,13]$. Figure 7 was obtained from the Moderate Resolution Imaging Spectroradiometer (MODIS) run by the NASA's Terra satellite. It shows aerosol optical depth distribution data for the month of September 2015.

Also, data offered by AERONET is used for ground based sites. ASHRAE explained this concept using the equation below. Measurements of AOD and precipitable water accumulated over a long period from the AERONET program were analyzed together with an angstrom exponent and used to determine the properties of aerosol optical properties

$$
\mathrm{AOD}=a_{0}+a_{1} \cdot \mathrm{AOD}_{\mathrm{MATCH}}+a_{2} \cdot \mathrm{AOD}_{\mathrm{MODIS}}
$$

where the coefficients $a_{0}, a_{1}$, and $a_{2}$ were determined by a line of best fit from plotted ground data. The current research adopts the AOD value offered by the AERONET.

\section{Results}

This section of the manuscript deals with weather elements that were studied in this manuscript. Statistical analyses of each of the weather elements are conducted. For each element, a monthly average and frequency are presented.

\subsection{Monthly Average and Frequency of \\ Weather Data in Seoul}

3.1.1. Monthly Average and Frequency of Temperature. In this chapter, we analyzed average and distribution values with measured data from 2011 to 2014 (total 35,040). Hourly weather data was divided by months and calculated maximum and minimum values.

Figure 8 shows hourly data from 2011 to 2014 in a monthly graph with a total of 35,040 measured datasets. The average dry temperature on the outside was $12.6^{\circ} \mathrm{C}$, the standard deviation was $11.3^{\circ} \mathrm{C}$, and minimum and maximum values were $-17.7^{\circ} \mathrm{C}$ and $36.2^{\circ} \mathrm{C}$, respectively. The monthly distribution graph of dry-bulb temperature shows the July and August months to be the hottest. In winter, typical weather distribution was the same with that of Seoul, where on some days temperatures go below $-10^{\circ} \mathrm{C}$, and frequency of temperature distribution was the highest at $20 \sim 30^{\circ} \mathrm{C}$. 

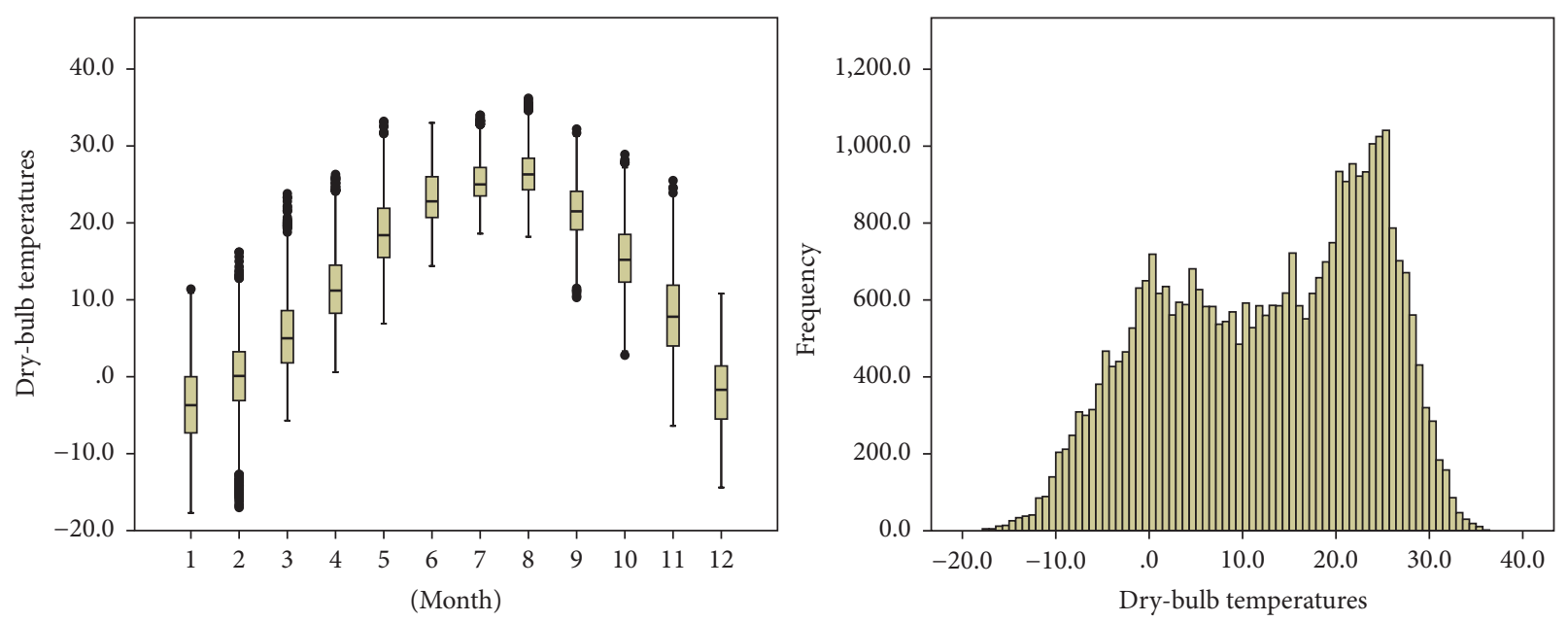

Figure 8: Monthly average and frequency of dry-bulb temperature (unit: ${ }^{\circ} \mathrm{C}$ ).
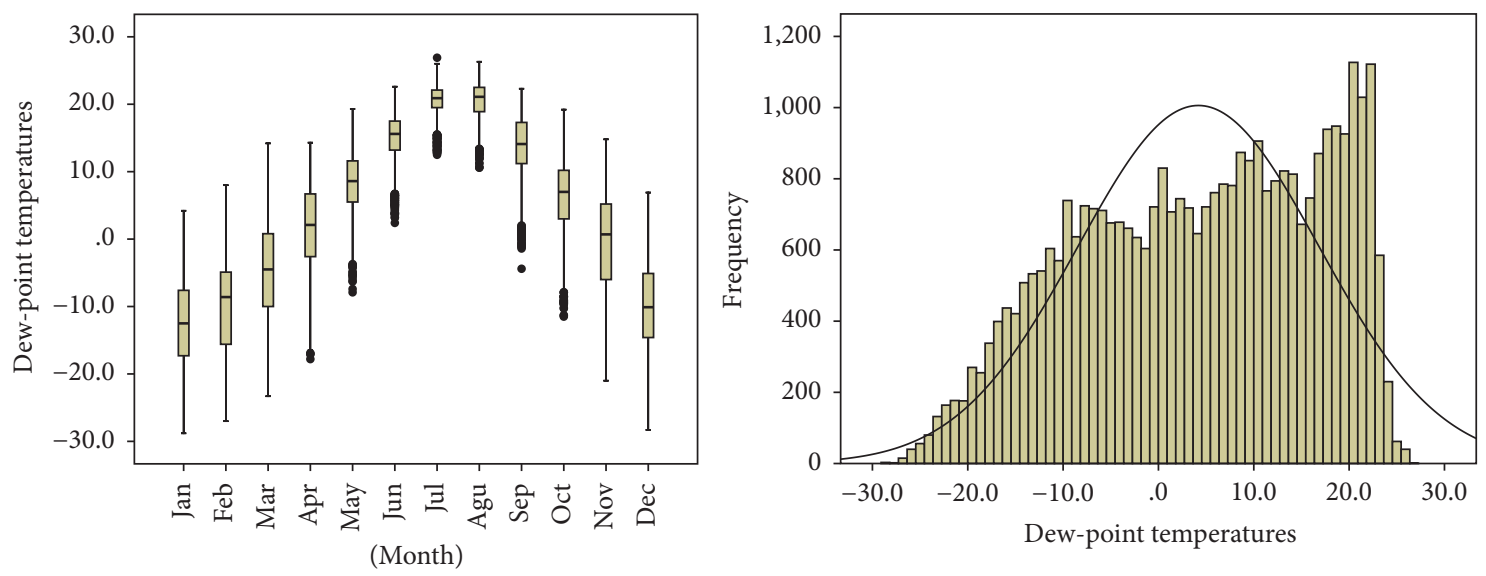

Figure 9: Monthly average and frequency of dew-point temperature (unit: ${ }^{\circ} \mathrm{C}$ ).

However, distribution frequency did not show a similar distribution to that of a distribution curve.

In case of dew-point temperature as shown in Figure 9, the average was at $4.19^{\circ} \mathrm{C}$, standard deviation was at $12.6^{\circ} \mathrm{C}$, and minimum and maximum were at $-28.8^{\circ} \mathrm{C}$ and $26.9^{\circ} \mathrm{C}$, respectively. Also, distributions of dew-point temperature and dry-bulb temperature showed a similar trend.

3.1.2. Monthly Average and Frequency of Relative Humidity and Atmospheric Station Pressure. The average relative humidity was at $59.8 \%$, standard deviation was at $19.9 \%$, and the minimum was $9 \%$, while the maximum was $100 \%$. Relative humidity in the months of June, July, and August was relatively larger, so we could anticipate that there are many hotter and moister days in summer. Unlike temperature distribution, frequency distribution relatively shows a figure of normal distribution curve. Therefore, distribution of $23 \sim 24^{\circ} \mathrm{C}$ which is the most pleasant temperature and the appearance frequency of relative humidity $40 \sim 60 \%$ were the highest by calculating temperature distribution of Korea only with frequency of temperature and humidity (see Figure 10).
In case of monthly distribution of atmospheric pressure, the average pressure was $100,586 \mathrm{~Pa}$, standard deviation was $808 \mathrm{~Pa}$, and the minimum was $97,510 \mathrm{~Pa}$, while the maximum was $102,820 \mathrm{~Pa}$ (see Figure 11). Also, the average of atmospheric pressure seems to decease during the summer period but increases gradually during the winter period.

3.1.3. Monthly Average and Frequency of Solar Radiation. From the analysis, average was $628 \mathrm{Wh} / \mathrm{m}^{2}$, standard deviation was $384 \mathrm{Wh} / \mathrm{m}^{2}$, the minimum was $1 \mathrm{Wh} / \mathrm{m}^{2}$, and the maximum was $1,280 \mathrm{Wh} / \mathrm{m}^{2}$. And monthly result was not large (see Figure 12). In addition, the behavior of EHR is similar to that shown by outdoor temperature.

As shown in Figure 13, the extraterrestrial direct solar radiation belonging to a particular location varies throughout the year. The average of extraterrestrial direct radiation was $1,367 \mathrm{Wh} / \mathrm{m}^{2}$, standard deviation was $33 \mathrm{Wh} / \mathrm{m}^{2}$, and the minimum was $1,321 \mathrm{Wh} / \mathrm{m}^{2}$, and the maximum was $1,415 \mathrm{Wh} / \mathrm{m}^{2}$. Extraterrestrial direct radiation presented large variations from month to month and extraterrestrial direct radiation of the summer period was the lowest. 

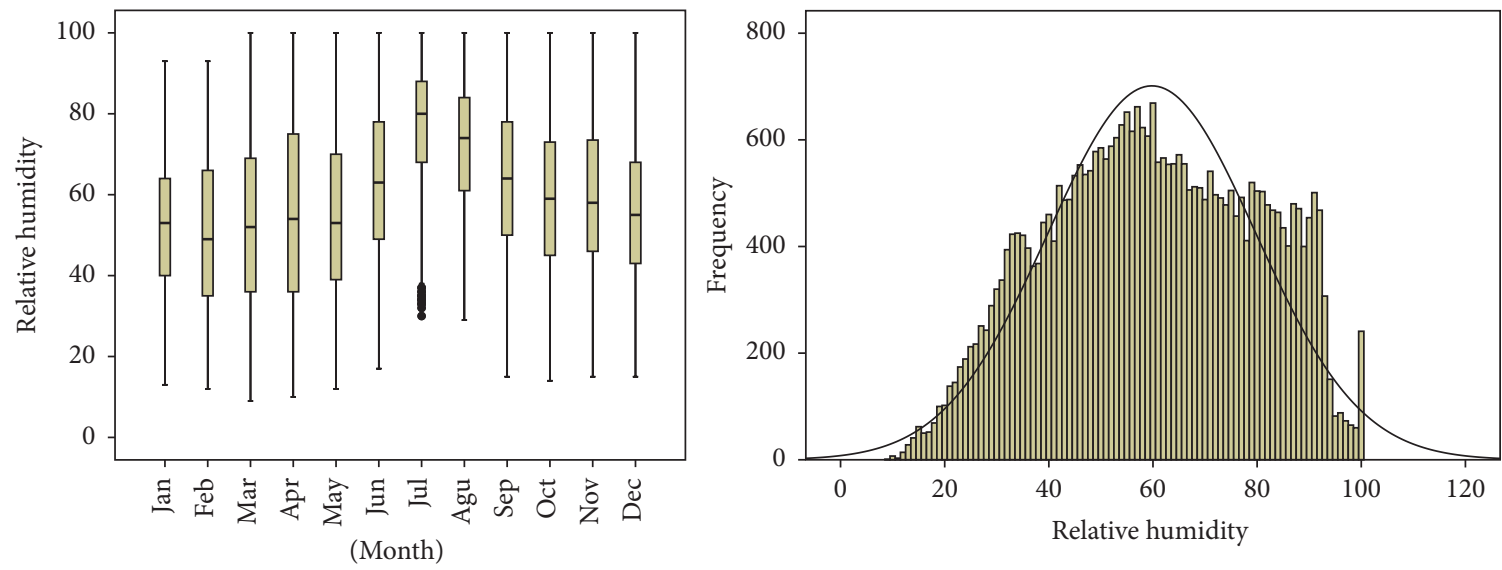

FIGURE 10: Monthly average and frequency of relative humidity (unit: \%).
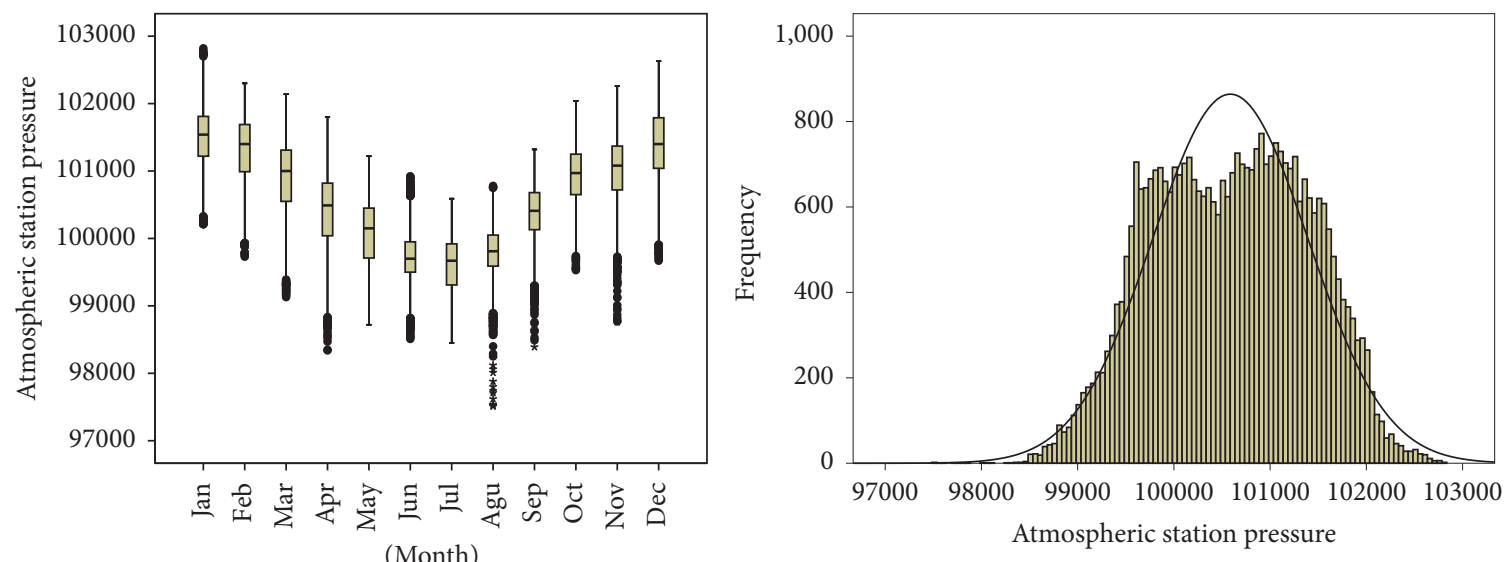

Figure 11: Monthly average and frequency of atmospheric station pressure (unit: $\mathrm{Pa}$ ).
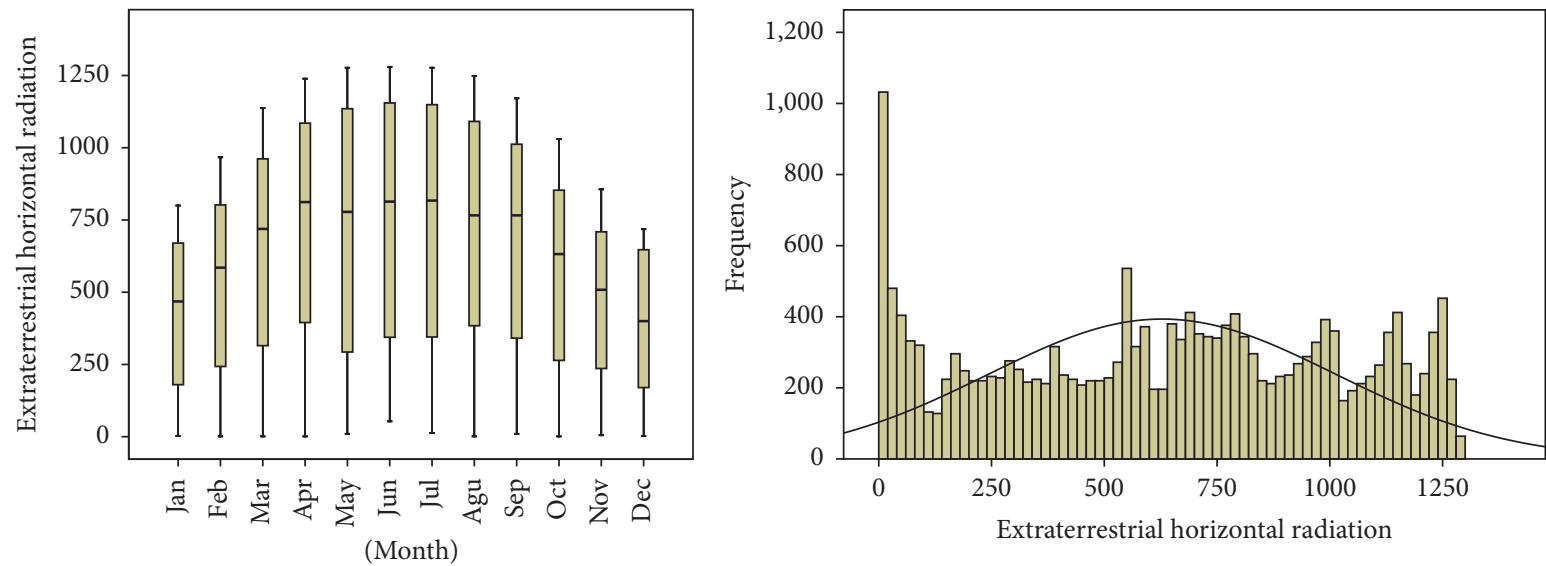

FIGURE 12: Monthly average and frequency of extraterrestrial horizontal radiation (unit: $\mathrm{Wh} / \mathrm{m}^{2}$ ).

Global horizontal radiation is presented as a graph of 17,692 measured datasets without the night time values which were not measured. Global horizontal radiation can be defined as a sum of direct horizontal radiation and diffuse horizontal radiation. Direct normal radiation used in this study and diffuse radiation were divided by PEREZ equation model using measured global horizontal radiation. The results of inside global horizontal radiation distribution were calculated as follows: average of $275.3 \mathrm{Wh} / \mathrm{m}^{2}$, a standard deviation of $228.6 \mathrm{Wh} / \mathrm{m}^{2}$, and a minimum and a maximum 

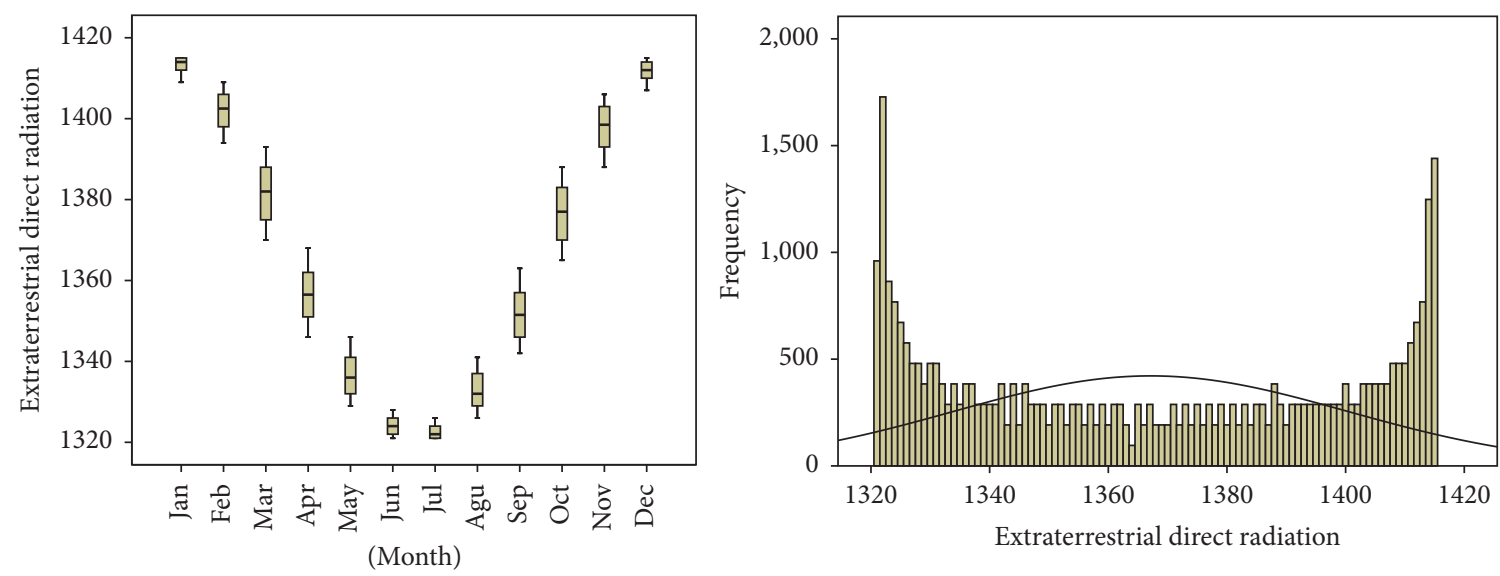

FIGURE 13: Monthly average and frequency of extraterrestrial direct radiation (unit: $\mathrm{Wh} / \mathrm{m}^{2}$ ).
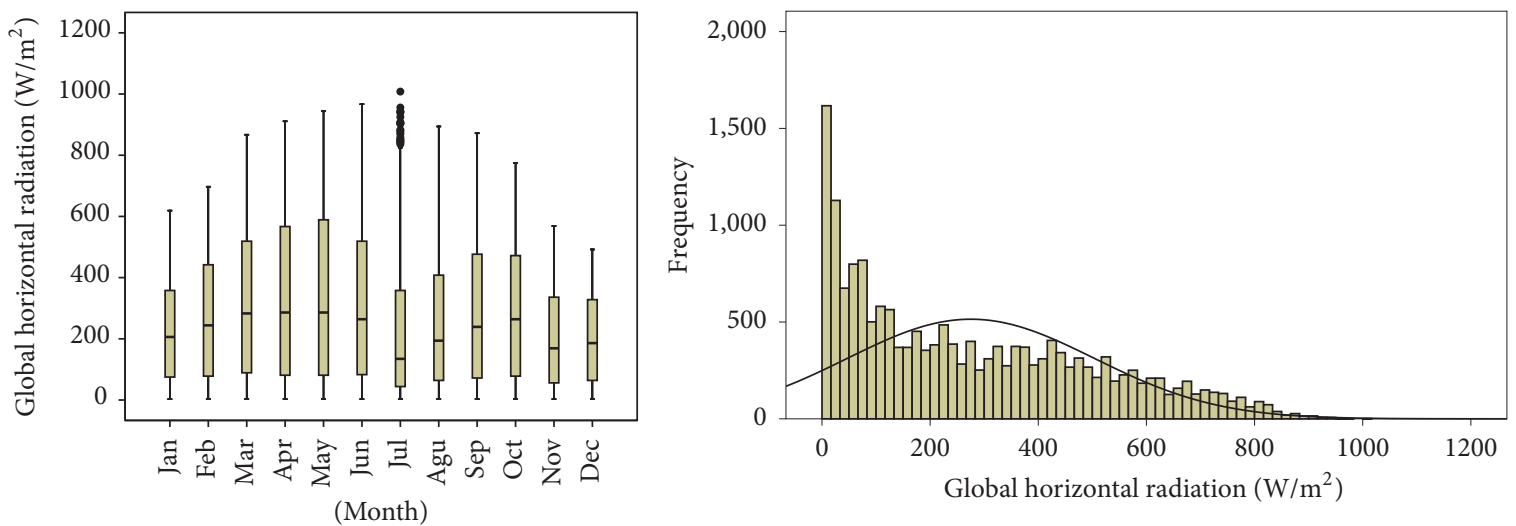

FIGURE 14: Monthly average and frequency of global horizontal radiation (unit: Wh/m²).

of $3 \mathrm{Wh} / \mathrm{m}^{2}$ and $1,008 \mathrm{Wh} / \mathrm{m}^{2}$, respectively (see Figure 14 ). Solar irradiance was expected to be the biggest because the solar altitude is the highest during the summer period. However, its absolute value was low due to the presence of high amounts of clouds and interference from other atmospheric conditions. This shows that ground temperature cannot be explained by only solar energy values as global solar radiation did not exactly coincide with temperature.

Direct normal radiation refers to the quantity of solar radiation reaching a unit surface of a given area when this surface is positioned perpendicularly to the rays of the sun. The average value of calculated direct normal radiation was $281 \mathrm{Wh} / \mathrm{m}^{2}$ and the standard deviation was $227 \mathrm{Wh} / \mathrm{m}^{2}$, while the minimum and maximum values were $1 \mathrm{Wh} / \mathrm{m}^{2}$ and $856 \mathrm{Wh} / \mathrm{m}^{2}$, respectively (see Figure 15 ). As expected, the measurement value in summer was relatively low and the amount of solar radiation in winter was twice as high as the radiation in summer

$$
\text { Direct }_{\text {normal radiation }}=\frac{\text { Direct }_{\text {horizontal radiation }}}{\sin \left(\text { solar }_{\text {height }}\right)} .
$$

The average diffuse radiation was $161 \mathrm{Wh} / \mathrm{m}^{2}$ and standard deviation was at $119 \mathrm{Wh} / \mathrm{m}^{2}$, while the minimum was
$3 \mathrm{Wh} / \mathrm{m}^{2}$ and the maximum $499 \mathrm{Wh} / \mathrm{m}^{2}$ (see Figure 16). Unlike with direct normal radiation, diffuse radiation seemed to increase in the first 6 months of the year and gradually decrease in the last 5 months of the years except for the month of July. The direct normal radiation is lower than global horizontal radiation because the value of global horizontal irradiation consists of a sum of direct normal radiation from the sun and the diffuse horizontal radiation that has been scattered by clouds and other atmospheric particles. As such subtracting the value of diffuse normal radiation from the value of global horizontal irradiation gives us an expectedly lower value of direct normal radiation.

The value of the ratio GHR/EHR is relatively smaller during the summer period than other seasons due to a decreasing global horizontal radiation. According to the analysis of the data, the average value and standard deviation of GHR/EHR were $36 \%$ and $22 \%$, respectively, while the minimum value was 0 and the maximum value was almost $100 \%$ (see Figure 17).

3.1.4. Monthly Average and Frequency of Sky Cover and Horizontal Infrared Radiation. The amount of clouds measured by KMA means the percentage of covered sky from 0 to 10 , where 0 represents the absence of cloud cover and 10 represents 

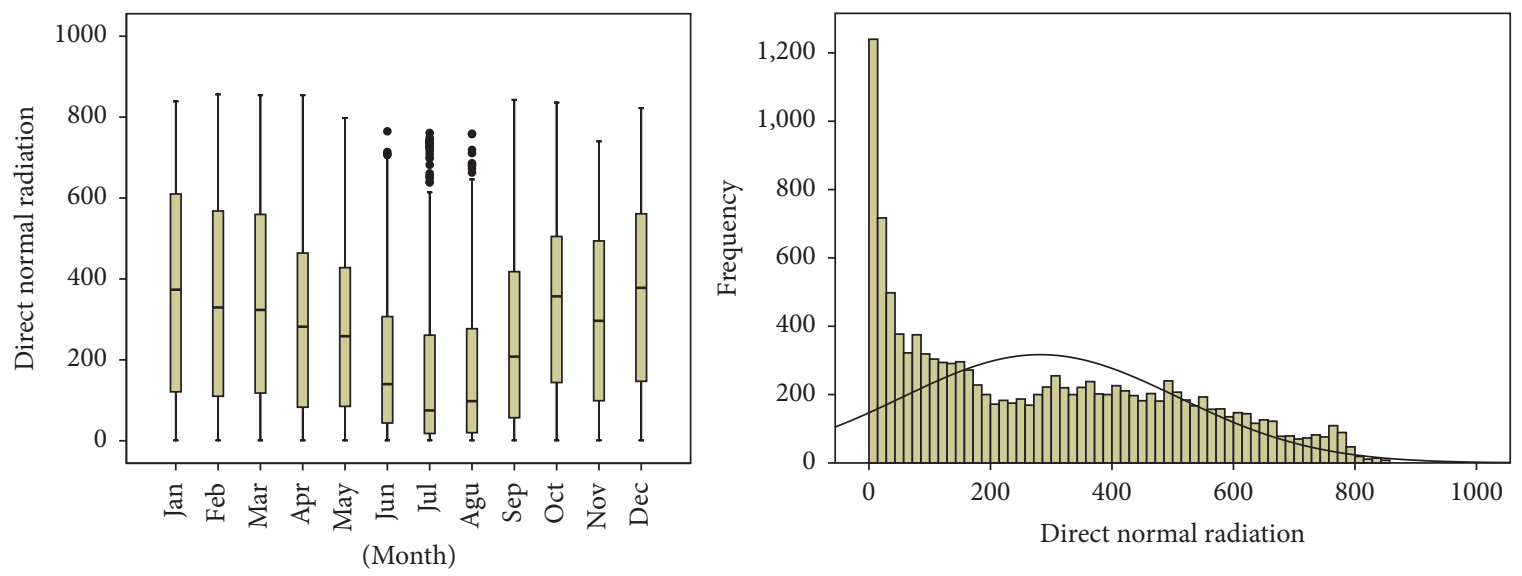

FIGURE 15: Monthly average and frequency of direct normal radiation (unit: Wh/ $/ \mathrm{m}^{2}$ ).
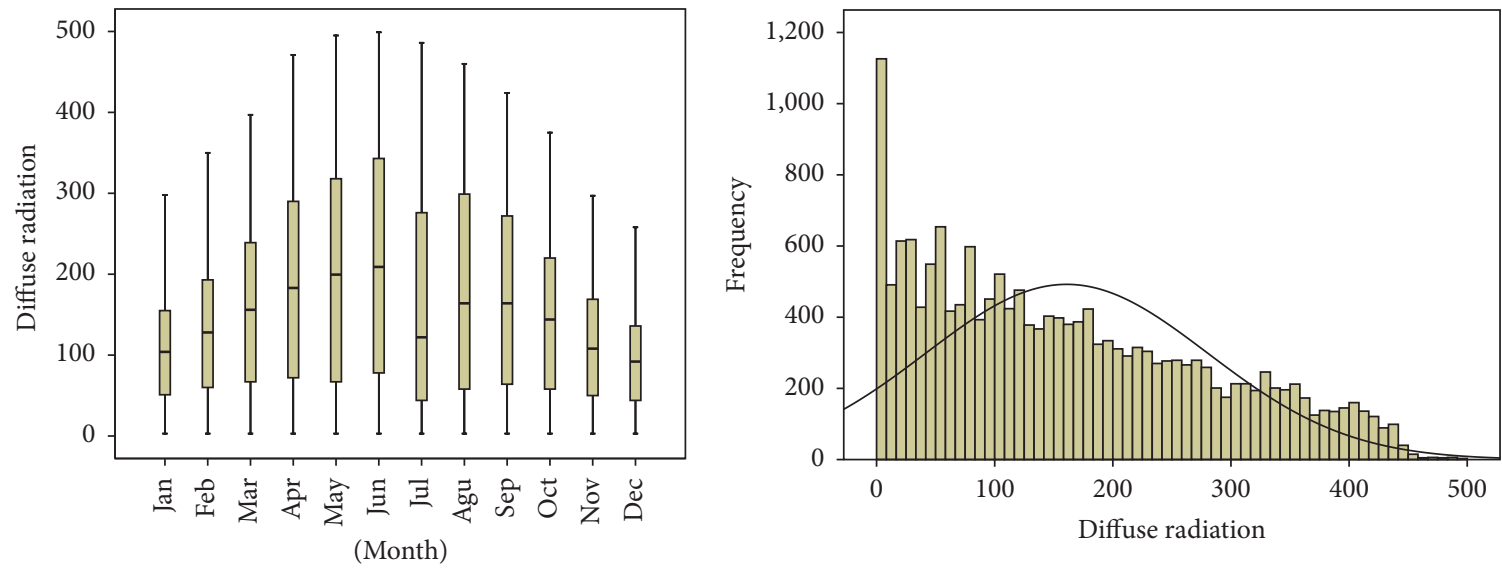

FIGURE 16: Monthly average and frequency of diffuse radiation (unit: $\mathrm{Wh} / \mathrm{m}^{2}$ ).
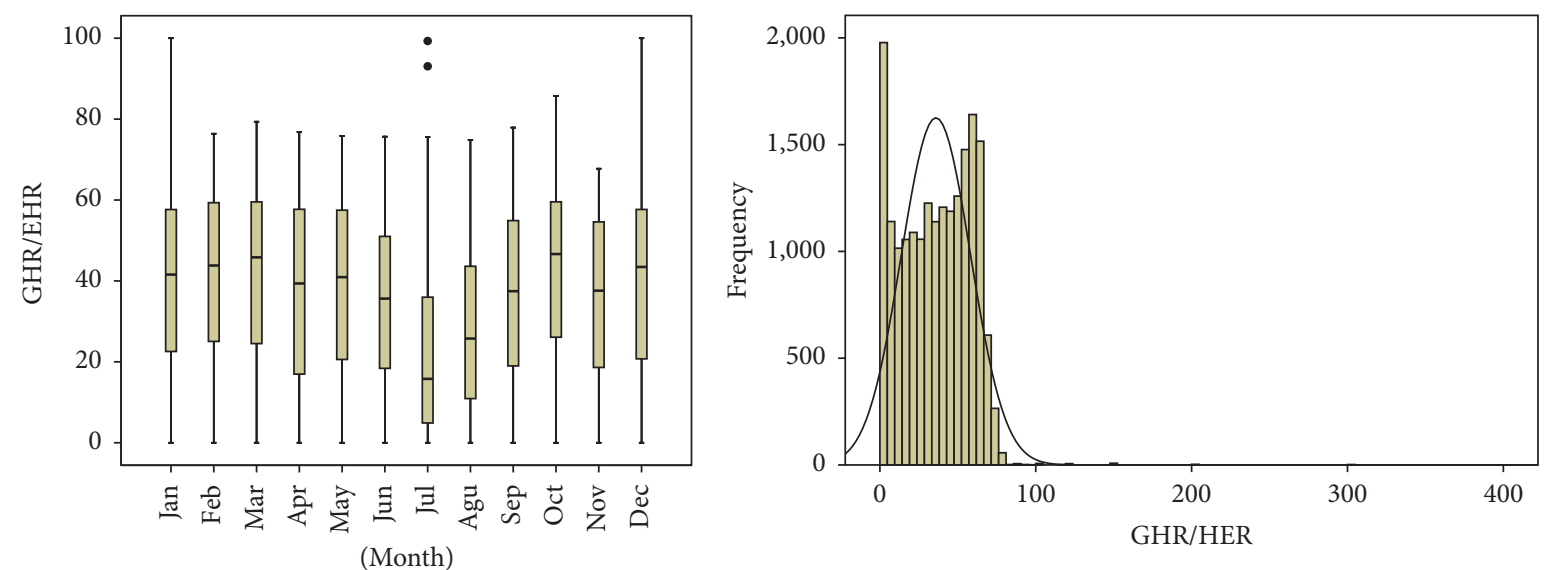

Figure 17: Monthly average and frequency of GHR/EHR (unit: \%).

maximum cloud cover. The result of analysis of the amount of clouds shows the average and standard deviation to be 4.81 and 3.93, respectively (see Figure 18). Also, the average of sky cover is the highest during the summer period and thus a possible indicator of the impact of sky cover on the amount of solar radiation reaching the earth. In other words, there exists a negative correlation between sky cover and sunlight.

The average horizontal infrared radiation was $638 \mathrm{Wh} / \mathrm{m}^{2}$ and the standard deviation was $318 \mathrm{Wh} / \mathrm{m}^{2}$, while the minimum and the maximum were $171 \mathrm{Wh} / \mathrm{m}^{2}$ and $1,337 \mathrm{Wh} / \mathrm{m}^{2}$, 

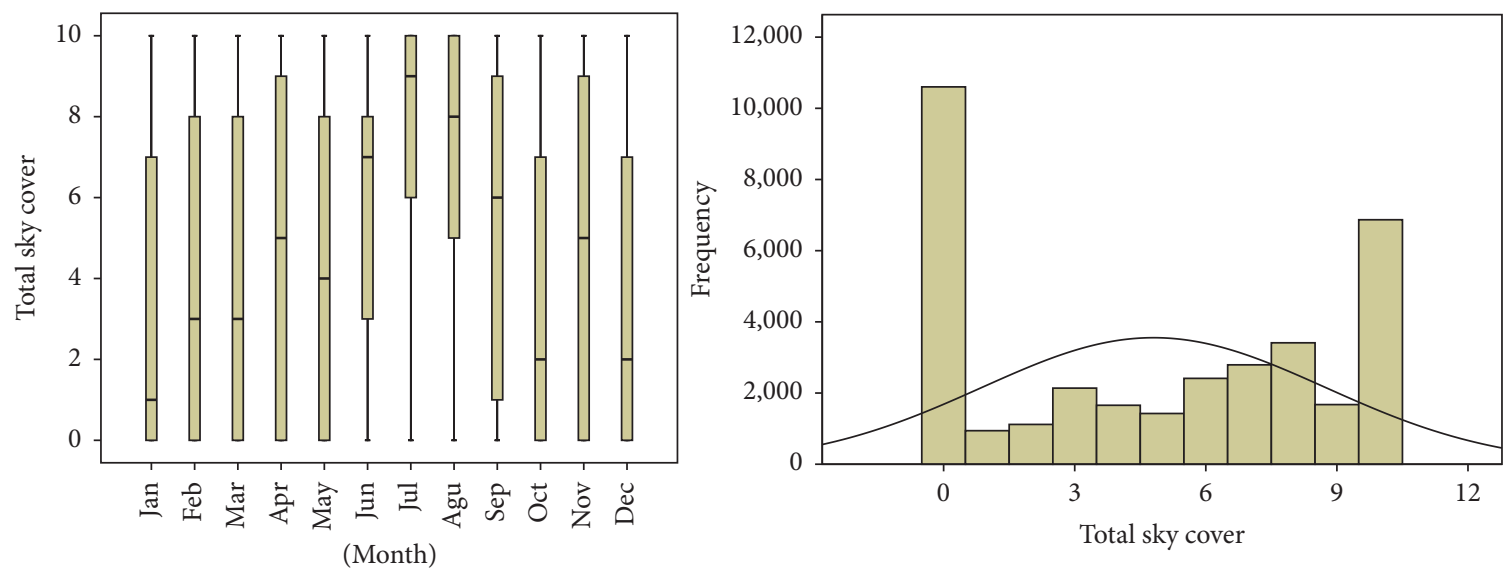

FIGURE 18: Monthly average and frequency of total sky cover.
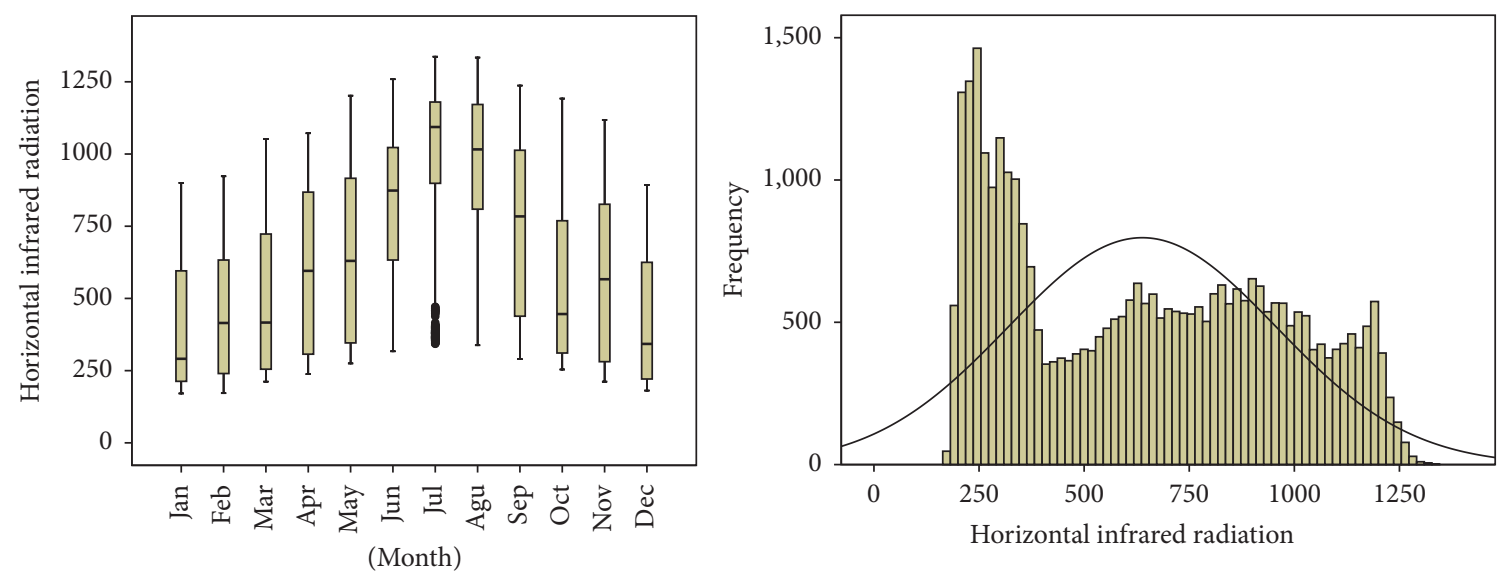

FIGURE 19: Monthly average and frequency of horizontal infrared radiation (unit: Wh/ $\mathrm{m}^{2}$ ).

respectively (see Figure 19). The average value of June, July, and August which is the hottest season showed the highest intensity of horizontal infrared radiation and generally it showed results closest to theoretically expectations. Although the temperature had many right sided result values from the center of normal distribution, horizontal infrared radiation had a higher frequency at the left side of the center.

3.1.5. Monthly Average and Frequency of Wind Speed and Visibility. The average wind velocity in Seoul was found to be $2.74 \mathrm{~m} / \mathrm{s}$ and had a standard deviation of $1.47 \mathrm{~m} / \mathrm{s}$. The minimum wind velocity was 0 , while the maximum was $11.4 \mathrm{~m} / \mathrm{s}$. From the analyzed results, it is easy to see the absence of high velocity such as typhoons during the past four years (see Figure 20).

Visibility is a meteorological element that shows the turbidity of the atmosphere. Visibility of an atmosphere on a given day can be defined as the maximum distance from which a person with normal vision can identify an object placed on the ground in bright light conditions such as during the day. Figure 21 shows the monthly average and frequency of visibility.
3.1.6. Monthly Average and Frequency of Aerosol Optical Depth and Precipitable Water. According to the 2014 annual report of air quality in Korea from the Ministry of Environment [14], in the case of $\mathrm{SO}_{2}$ of Seoul, annual mean pollution level tended to decrease; however, it showed no change from 2002 to 2009. Although the average of pollution level from 2010 to 2012 is $0.005 \mathrm{ppm}$, the average pollution levels in 2013 were $0.006 \mathrm{ppm}$, which is a $0.001 \mathrm{ppm}$ increase from the year 2012 .

In the past four years, according to measured levels of $\mathrm{SO}_{2}$, the monthly average of summer was lower than that of winter and it showed similar tendencies with atmospheric pressure. The quantitative result showed an average and standard deviation of $0.005 \mathrm{ppm}$ and $0.003 \mathrm{ppm}$, respectively, as well as a minimum of $0.001 \mathrm{ppm}$ and a maximum of 0.033 ppm (see Figure 22).

Nowadays, people are more interested in microaerosol due to the air pollution by the Asian dust phenomenon. Microaerosol is divided into PM-10 and PM-2.5 based on diameter. PM-10 is smaller than ten thousandths $\mathrm{mm}$ and PM-2.5 is smaller than 2.5 thousandths mm. Microaerosol is the emission of a mixture of solid and liquid particles in the air. It can also be a result of chemical reactions or simply due 

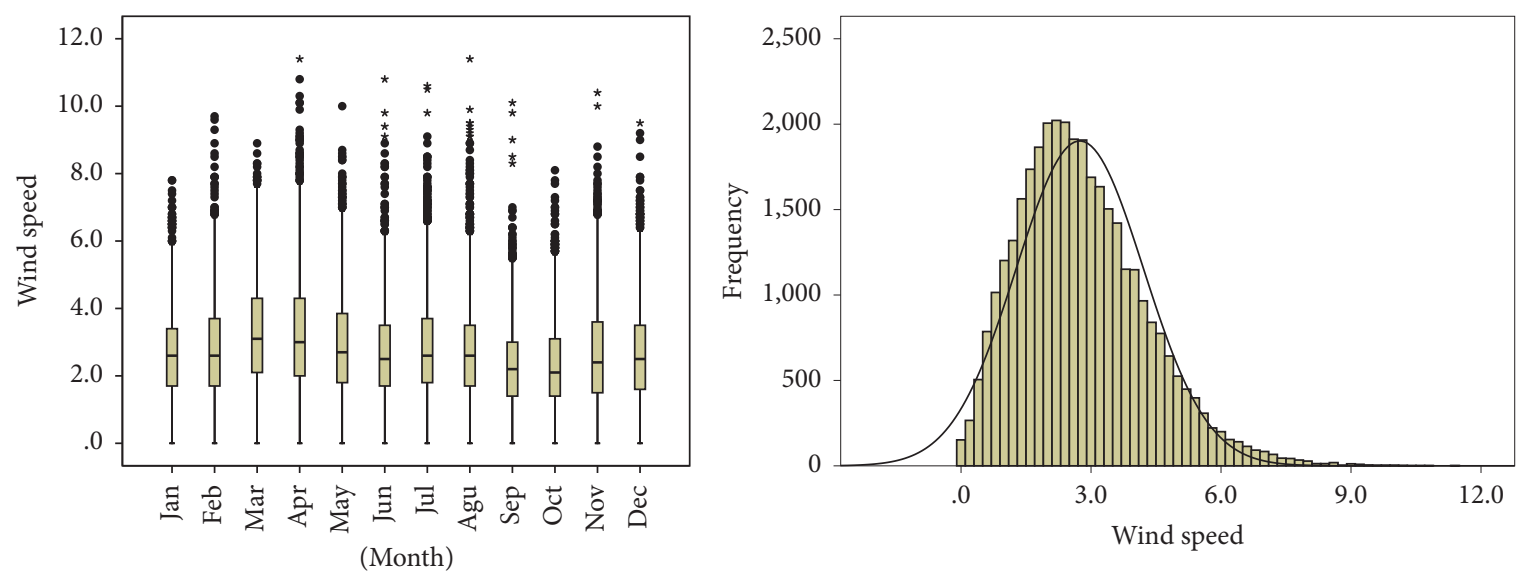

FIGURE 20: Monthly average and frequency of wind speed (unit: $\mathrm{m} / \mathrm{s}$ ).
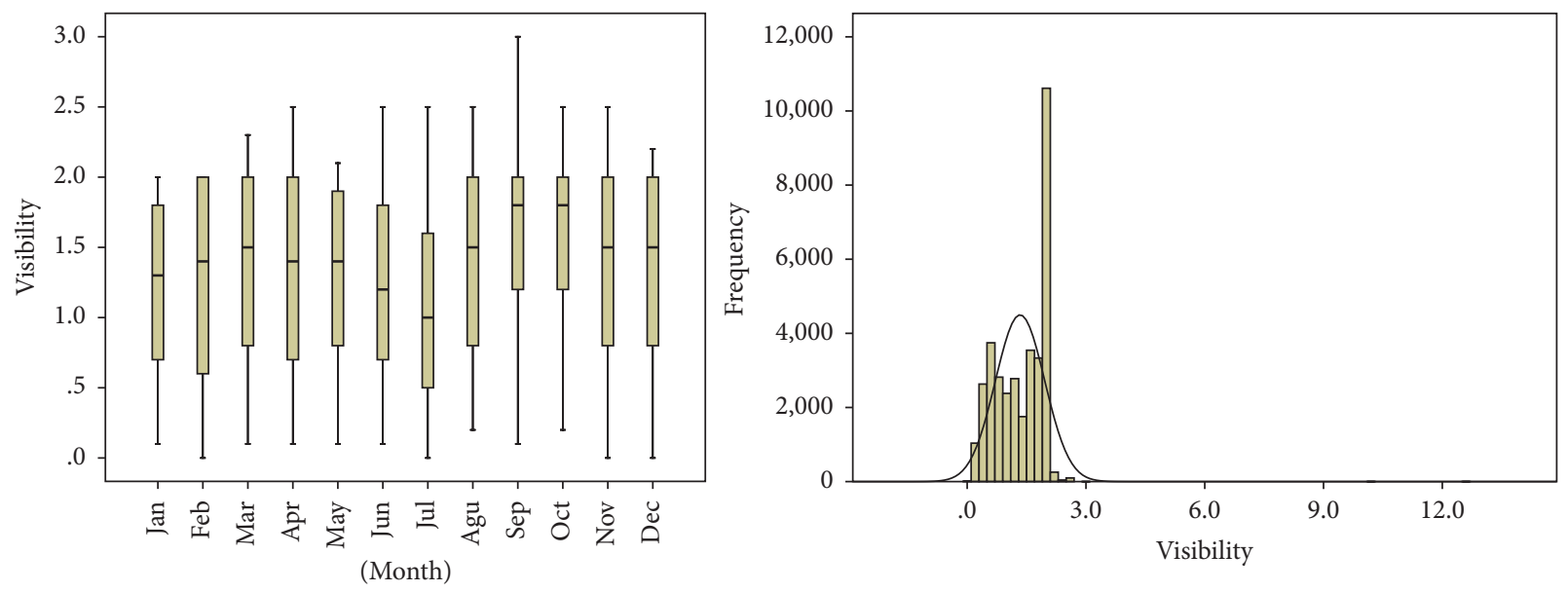

FIGURE 21: Monthly average and frequency of visibility (unit: km).
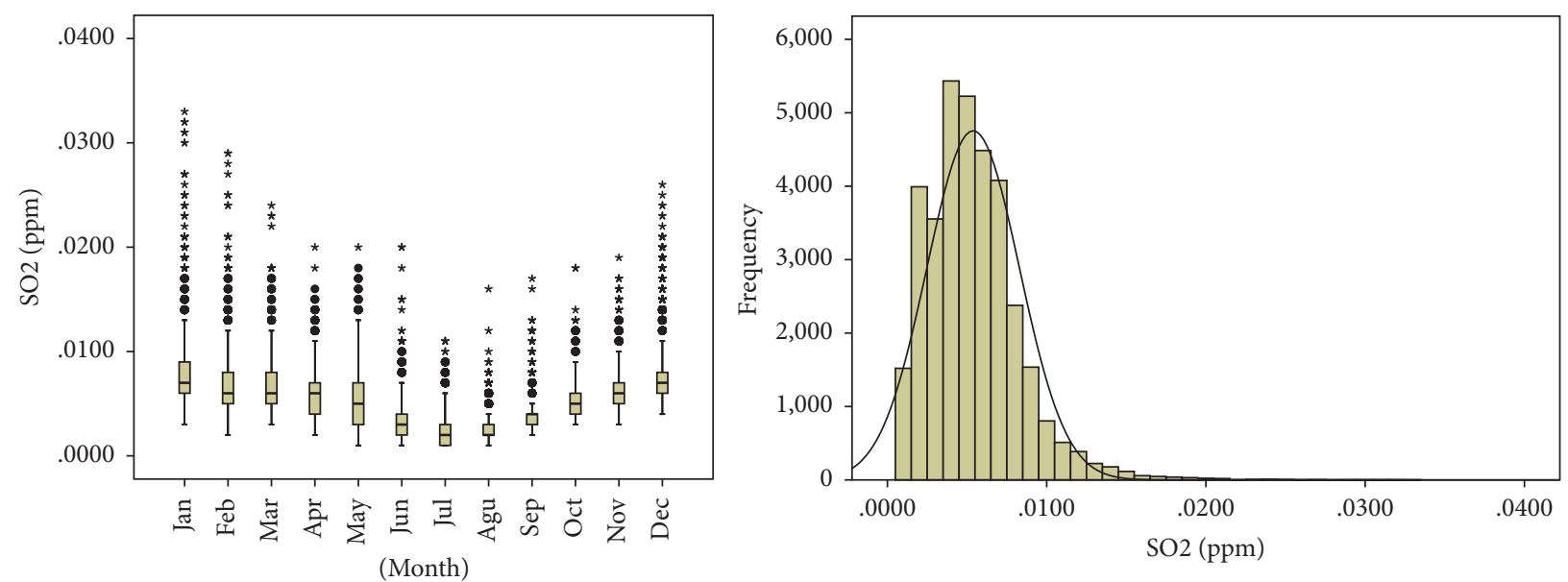

FIGURE 22: Monthly average and frequency of $\mathrm{SO}_{2}$ (unit: ppm).

to natural causes. PM-10 repeatedly increased and decreased fluctuating within $51 \sim 61 \mu \mathrm{g} / \mathrm{m}^{3}$ from 1998 to 2006, decreased from 2007 , and got lower to $54 \mu \mathrm{g} / \mathrm{m}^{3}$ in 2008 . Then it kept dropping until $45 \mu \mathrm{g} / \mathrm{m}^{3}$ in 2012 and increased from $45 \mu \mathrm{g} / \mathrm{m}^{3}$ to $49 \mu \mathrm{g} / \mathrm{m}^{3}$ in 2013 .
In the result of monthly data analysis of PM-10 with a total of 34,605 measured datasets except missing data, its gap between maximum and minimum is the highest. The average value, standard deviation, and the minimum and maximum values of PM-10 were found to be $43.5 \mu \mathrm{g} / \mathrm{m}^{3}$, 

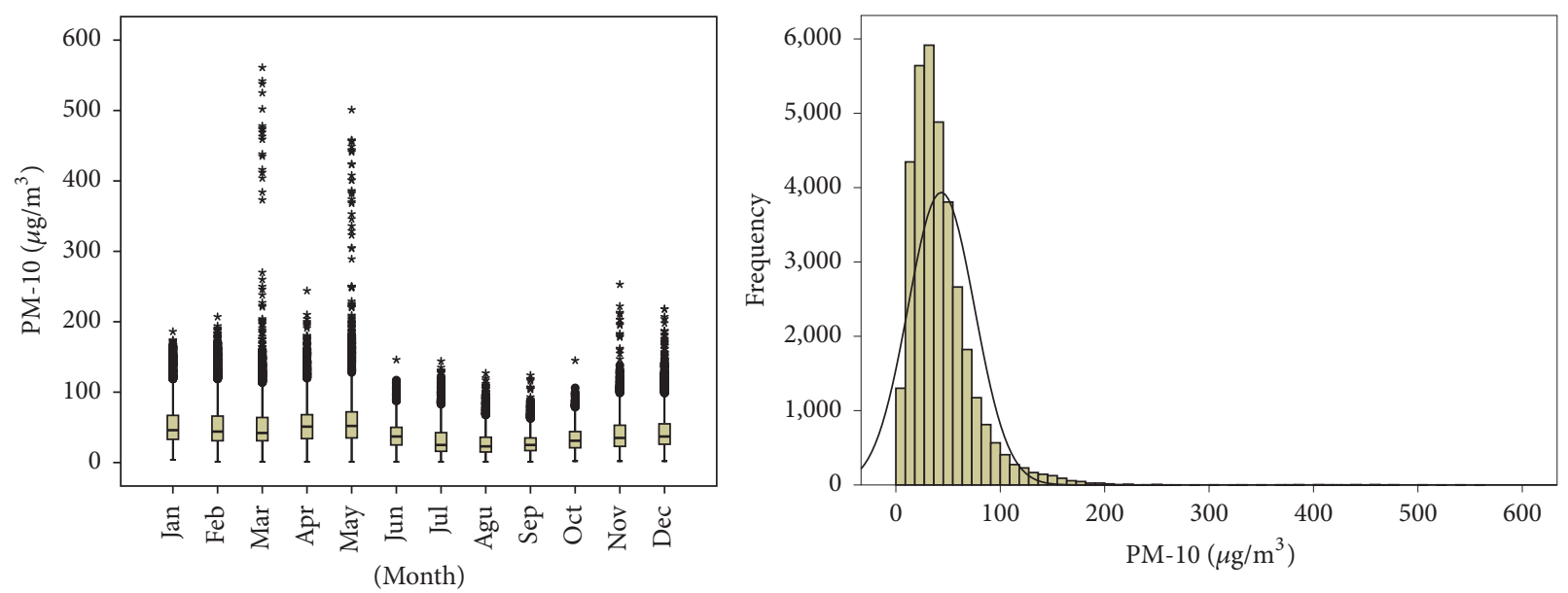

FIgURE 23: Monthly average and frequency of PM-10 (unit: $\mu \mathrm{g} / \mathrm{m}^{3}$ ).
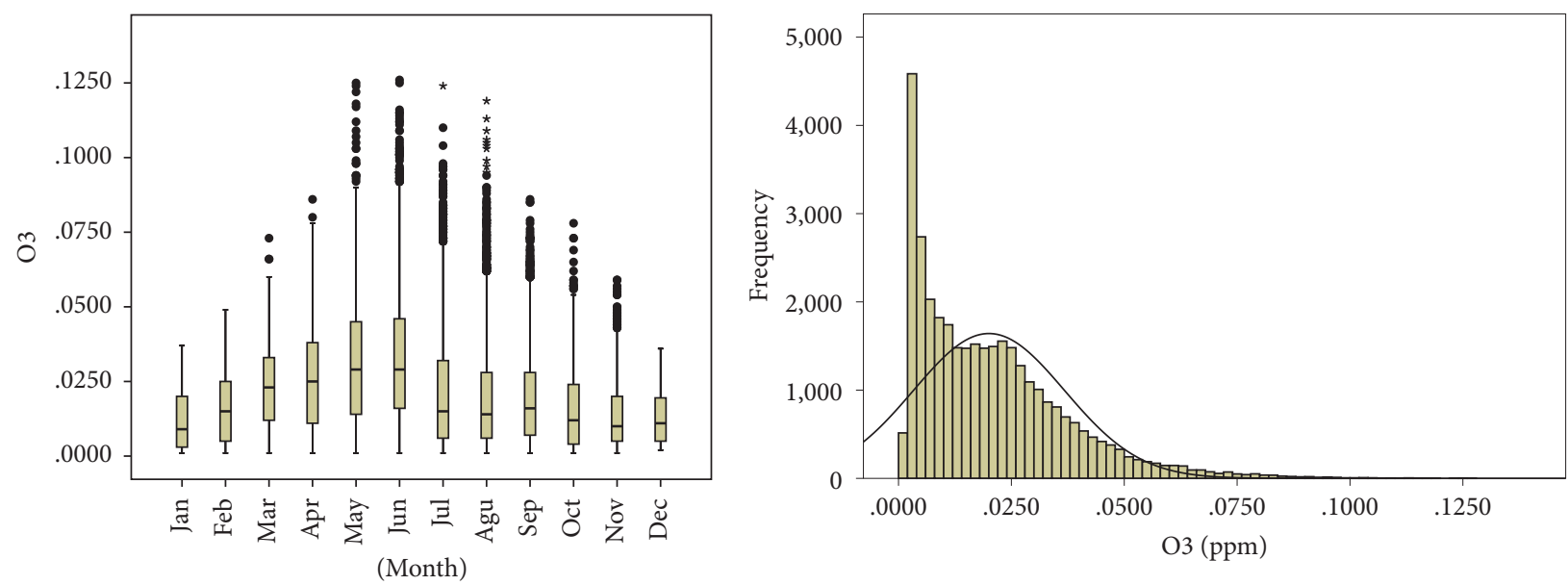

FIGURE 24: Monthly average and frequency of $\mathrm{O}_{3}$ (unit: ppm).

$31.9 \mu \mathrm{g} / \mathrm{m}^{3}, 1 \mu \mathrm{g} / \mathrm{m}^{3}$, and $561 \mu \mathrm{g} / \mathrm{m}^{3}$ in that respective order (see Figure 23).

The annual average of the pollution level of Seoul maintained a certain level since 1998, but after 2010, it increased by 0.001 ppm every year and it was at $0.026 \mathrm{ppm}$ in 2013 .

In the result of monthly data analysis of $\mathrm{O}_{3}$ with a total of 34,605 measured datasets except for discrete missing data, the average was found to be $0.02 \mathrm{ppm}$ and standard deviation was found to be $0.016 \mathrm{ppm}$, while the minimum was found at $0.01 \mathrm{ppm}$ and the maximum at $0.126 \mathrm{ppm}$ (see Figure 24).

$\mathrm{NO}_{2}$ became worse from 1998 to 2001, while it maintained a certain level from 2009 to 2012. It led to an increase in average pollution level to $0.026 \mathrm{ppm}$ from 2007 to 2008 . And it decreased from 2009 to 2012 and increased again from $0.001 \mathrm{ppm}$ to $0.024 \mathrm{ppm}$ in 2013 . In the result of analysis of the distribution of $\mathrm{NO}_{2}$ with a total of 34,428 measured datasets, the average amount of $\mathrm{NO}_{2}$ was found to be $0.035 \mathrm{ppm}$ (see Figure 25).

Carbon monoxide is a colorless and odorless toxic gas which is generated at incomplete combustion. Its major discharge source is transportation and it is also generated from burning of fuel in industrial processes. There are spontaneous generation such as a forest fire, kitchen, cigarette smoke, and district heating. It reduces the transporting capability of hemoglobin by changing hemoglobin into carbonyl hemoglobin $(\mathrm{COHb})$. Also a high concentration of carbon monoxide is toxic and very harmful to human beings. As it turns out, CO shows a decreasing tendency from 1998 to 2014, while it showed maintained levels at 0.6 ppm from 2005 to 2008 and decreased slightly from 2009 to 2013 coming to $0.5 \mathrm{ppm}$.

In the result of measurement of $\mathrm{CO}$ with a total of 34,630 measured datasets, the average was found to be $0.517 \mathrm{ppm}$ and the standard deviation was found to be $0.332 \mathrm{ppm}$, while the minimum and maximum stood at $0.1 \mathrm{ppm}$ and $2.9 \mathrm{ppm}$, respectively (see Figure 26).

Aerosols are solid and liquid tiny particles that float in the air. Their sizes can range from $0.001 \mu \mathrm{m}$ to $100 \mu \mathrm{m}$. The particles diffuse and absorb sunlight, hence reducing the temperatures reaching the earth. Also, they can block people's view and may lead to unusual weather conditions.

The results of analysis with a total of 8,138 measured datasets that were obtained from AERONET showed an average of 0.653 , a standard deviation of 0.606 , and a 

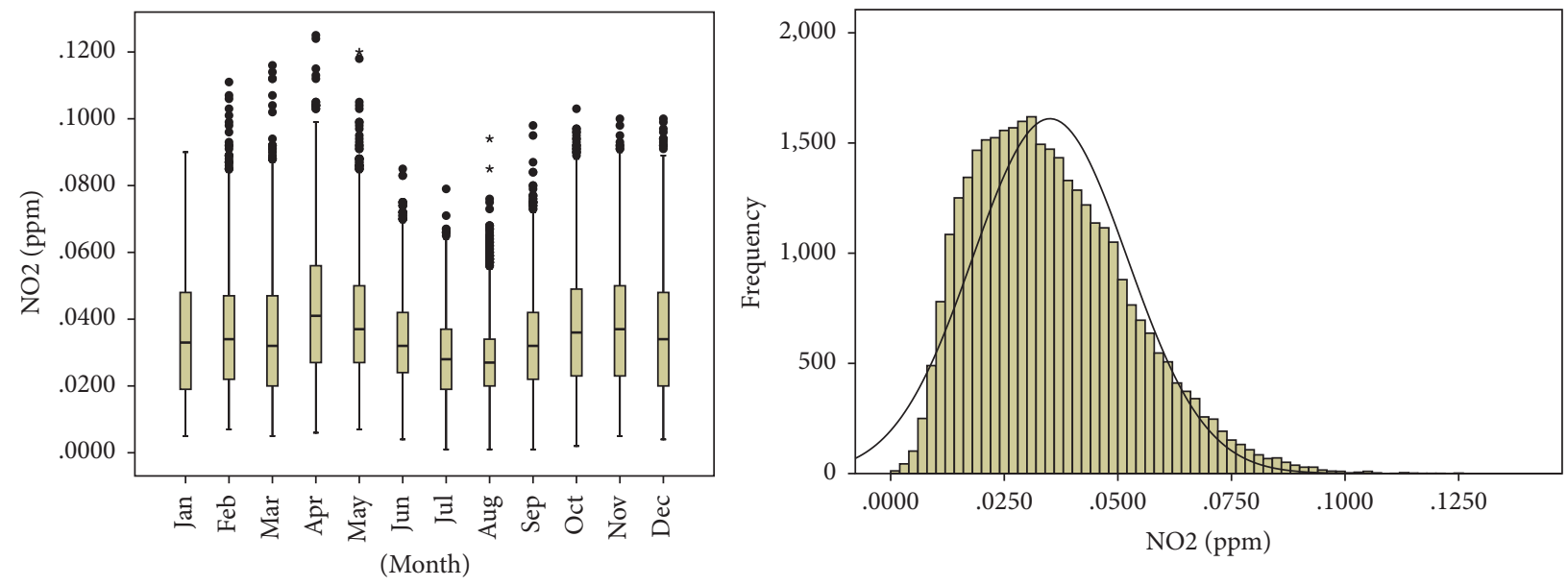

Figure 25: Monthly average and frequency of $\mathrm{NO}_{2}$ (unit: ppm).
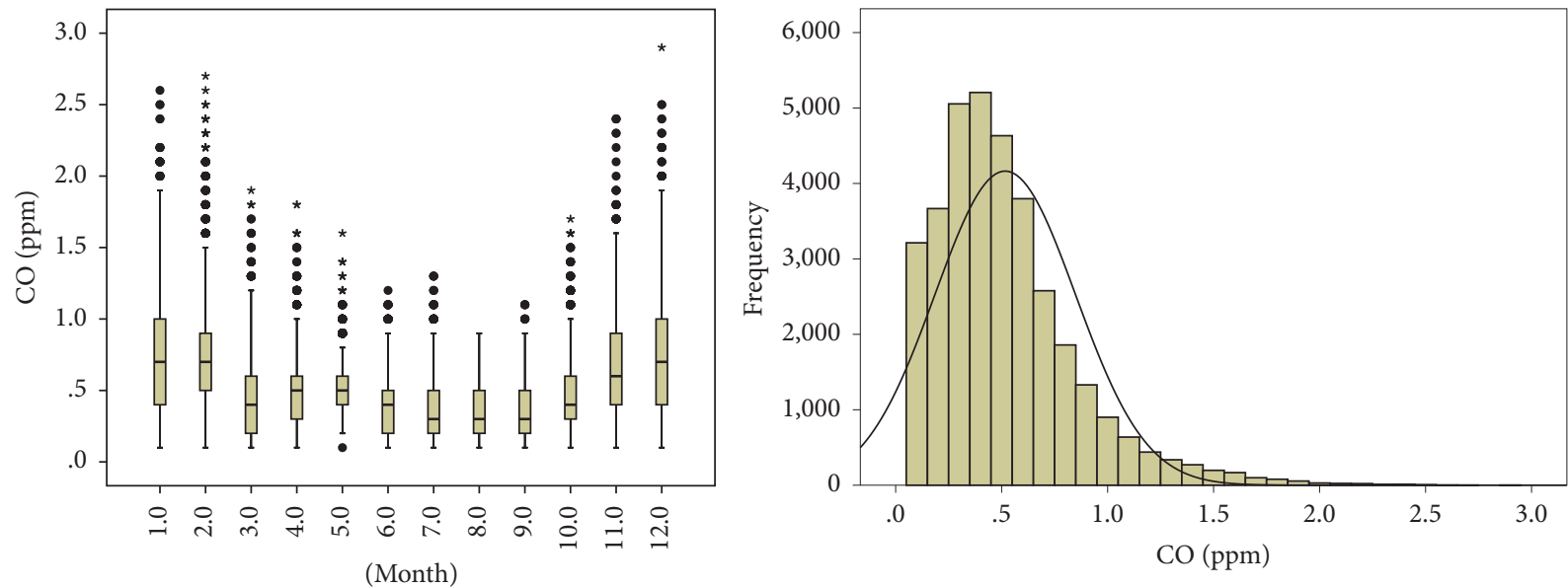

FIGURE 26: Monthly average and frequency of CO (unit: ppm).
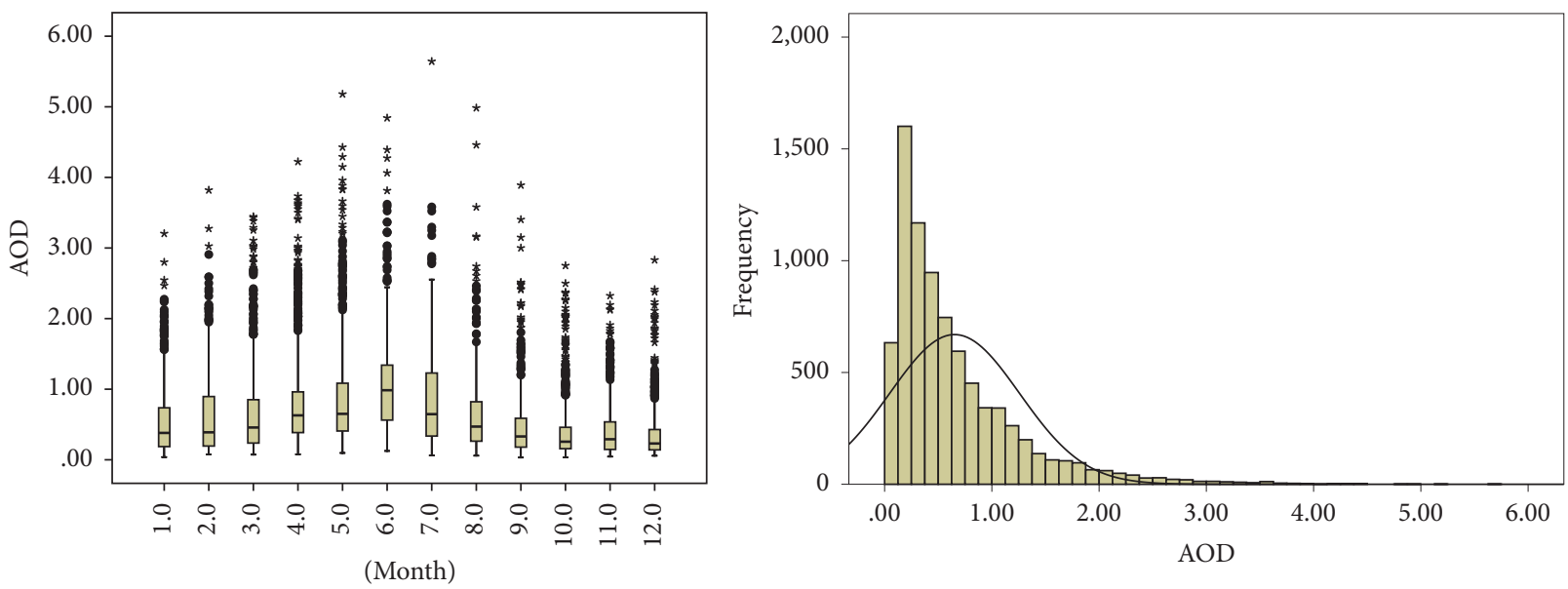

FIGURE 27: Monthly average and frequency of AOD.

minimum and maximum value of 0.032 and 5.64, respectively (see Figure 27). In the case of AOD, the data of June and July is relatively high and it did not show similar tendencies to previously analyzed airborne dust data.
In the result of analysis of precipitable water distribution with a total of 5,959 measured data that was obtained from AERONET, the average amount of precipitable water was shown to be $1.346 \mathrm{~cm}$ and the standard deviation was at 


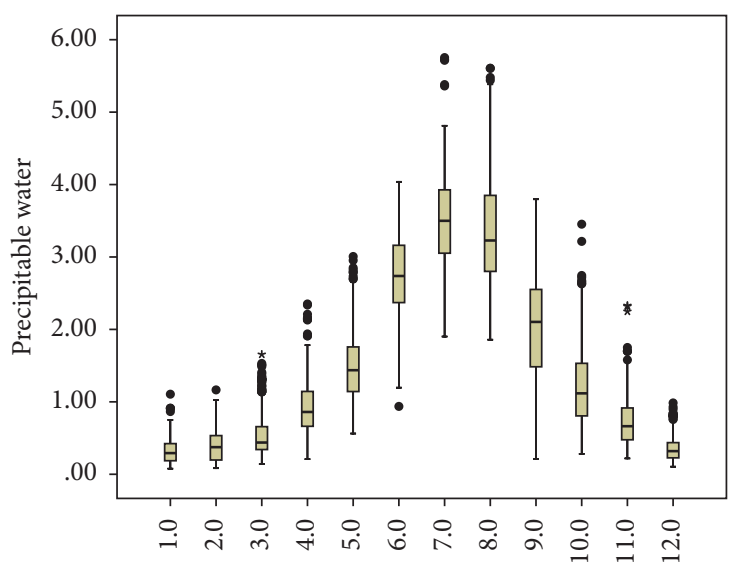

(Month)

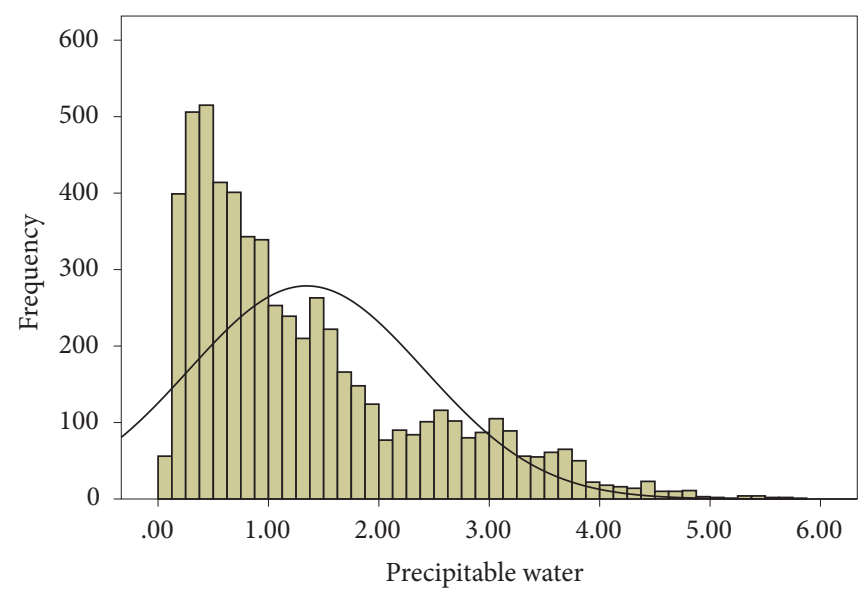

FIGURE 28: Monthly average and frequency of precipitable water (unit: $\mathrm{cm}$ ).

TABLE 1: Correlation of temperature and solar radiation in cooling period.

\begin{tabular}{|c|c|c|c|c|c|c|c|c|c|}
\hline \multirow{2}{*}{ Variables } & \multirow{2}{*}{ Mean } & \multirow{2}{*}{ Std. deviation } & \multirow{2}{*}{$N$} & \multicolumn{6}{|c|}{ Pearson correlation } \\
\hline & & & & (1) & (2) & (3) & (4) & (5) & (6) \\
\hline (1) Dry-bulb temperatures $\left({ }^{\circ} \mathrm{C}\right)$ & 24.57 & 4.38 & 7956 & 1 & & & & & \\
\hline (2) Dew-point temperatures $\left({ }^{\circ} \mathrm{C}\right)$ & 15.49 & 5.91 & 7956 & $.439^{* *}$ & 1 & & & & \\
\hline (3) Horizontal infrared radiation $\left(\mathrm{Wh} / \mathrm{m}^{2}\right)$ & 861.50 & 284.21 & 7956 & $.111^{* *}$ & $.620^{* *}$ & 1 & & & \\
\hline (4) Global horizontal radiation $\left(\mathrm{Wh} / \mathrm{m}^{2}\right)$ & 298.99 & 245.29 & 7956 & $.289^{* *}$ & $-.350^{* *}$ & $-.410^{* *}$ & 1 & & \\
\hline (5) Direct normal radiation $\left(\mathrm{Wh} / \mathrm{m}^{2}\right)$ & 148.65 & 190.64 & 7956 & $.107^{* *}$ & $-.444^{* *}$ & $-.615^{* *}$ & $.793^{* *}$ & 1 & \\
\hline (6) Diffuse radiation $\left(\mathrm{Wh} / \mathrm{m}^{2}\right)$ & 195.10 & 133.45 & 7956 & $.344^{* *}$ & $-.196^{* *}$ & $-.178^{* *}$ & $.852^{* *}$ & $.402^{* *}$ & 1 \\
\hline
\end{tabular}

${ }^{* *}$ Correlation is significant at the 0.01 level (2-tailed). Correlation is significant at the 0.05 level (2-tailed).

$1.066 \mathrm{~cm}$, while the minimum and maximum amounts stood at $0.077 \mathrm{~cm}$ and $5.75 \mathrm{~cm}$ in that order (see Figure 28). In the result of monthly observation, it showed the highest level in July and August and did not exceed 1 in the winter season. Through these results, it can be concluded that the amount of water vapor in the atmosphere contributes to the decrease in solar radiation as it is the highest in June, July, and August.

\subsection{Monthly Average and Frequency of Weather Data in Seoul}

\subsubsection{Statistical Correlation between Temperature and Solar} Radiation. The correlation analysis results between the temperature levels experienced during the cooling period (May to September) and solar radiation during daytime (from 7 a.m. to 7 p.m.) show that the correlation coefficient between total solar radiation and dry-bulb temperature is no more than 0.3 , and wet bulb temperature is inversely proportional to the total solar radiation. Correlation coefficient between diffusion solar radiation and dry-bulb temperature is 0.344 and is 0.107 in case of beam radiation and dry-bulb temperature, which is relatively low. Generally, dew-point temperature has high correlation coefficients with dry-bulb temperature and horizontal infrared radiation that is usually higher than 0.4 . However, correlation with dry-bulb temperature and horizontal infrared radiation is exceedingly low at 0.111 in this case. This may be due at an error caused by the time lag. In the relation between dry-bulb temperature and beam radiation, the correlation is also relatively underestimated by the factors such as time lag on the earth. Also, negative correlations shown between AOD, dew-point temperature, and solar irradiation could be attributed to the influence of time lag or other variables. Table 1 shows the analysis of the correlation between temperature and solar radiation in cooling period.

The results obtained from analyzing the correlation between temperature levels during the heating period (October-April) and solar radiation during daytime show no significant difference with that of the cooling period. On the contrary, certain data showed a declined correlation. Drybulb temperature and beam radiation, different from cooling period, denote negative correlation, which means that there is no correlation. Dew-point temperature and diffusion solar radiation both show negative correlation during the cooling period, but positive correlations were found during the heating period.

Relationship between horizontal infrared radiation and solar irradiation shows a similar tendency, though the correlation value is slightly low. Thus, for the heating period, discordant results between the independent variables and dependent variables were found, showing no correlation within variables. Table 2 shows the analysis of correlation of temperature and solar radiation during the heating period.

3.2.2. Statistical Correlation between Solar Radiation and Solar Altitude. Theoretically, the relationship between solar radiation and solar altitude is dependent upon the angle of 
TABLE 2: Correlation of temperature and solar radiation in heating period.

\begin{tabular}{|c|c|c|c|c|c|c|c|c|c|}
\hline \multirow{2}{*}{ Variables } & \multirow{2}{*}{ Mean } & \multirow{2}{*}{ Std. deviation } & \multirow{2}{*}{$N$} & \multicolumn{6}{|c|}{ Pearson correlation } \\
\hline & & & & (1) & $(2)$ & (3) & (4) & (5) & $(6)$ \\
\hline (1) Dry-bulb temperatures $\left({ }^{\circ} \mathrm{C}\right)$ & 7.01 & 8.49 & 8480 & 1 & & & & & \\
\hline (2) Dew-point temperatures $\left({ }^{\circ} \mathrm{C}\right)$ & -4.70 & 9.42 & 8480 & $.804^{* *}$ & 1 & & & & \\
\hline (3) Horizontal infrared radiation $\left(\mathrm{Wh} / \mathrm{m}^{2}\right)$ & 520.51 & 249.65 & 8480 & $.379^{* *}$ & $.618^{* *}$ & 1 & & & \\
\hline (4) Global horizontal radiation $\left(\mathrm{Wh} / \mathrm{m}^{2}\right)$ & 287.98 & 208.35 & 8480 & $.228^{* *}$ & $-.082^{* *}$ & $-.294^{* *}$ & 1 & & \\
\hline (5) Direct normal radiation $\left(\mathrm{Wh} / \mathrm{m}^{2}\right)$ & 271.47 & 253.63 & 8480 & $-.129^{* *}$ & $-.385^{* *}$ & $-.589^{* *}$ & $.753^{* *}$ & 1 & \\
\hline (6) Diffuse radiation $\left(\mathrm{Wh} / \mathrm{m}^{2}\right)$ & 148.41 & 95.83 & 8480 & $.399^{* *}$ & $.189^{* *}$ & $.074^{* *}$ & $.735^{* *}$ & $.185^{* *}$ & 1 \\
\hline
\end{tabular}

${ }^{* *}$ Correlation is significant at the 0.01 level (2-tailed). Correlation is significant at the 0.05 level (2-tailed).

TABLE 3: Correlation of solar radiation and solar altitude.

\begin{tabular}{|c|c|c|c|c|c|c|}
\hline \multirow{2}{*}{ Variables } & \multirow{2}{*}{ Mean } & \multirow{2}{*}{ Std. deviation } & \multirow{2}{*}{$N$} & \multicolumn{3}{|c|}{ Pearson correlation } \\
\hline & & & & (1) & $(2)$ & (3) \\
\hline (1) Global horizontal radiation $\left(\mathrm{Wh} / \mathrm{m}^{2}\right)$ & 275.29 & 228.63 & 17692 & 1 & & \\
\hline (2) GHR/HER (\%) & 38.54 & 20.65 & 17687 & $.776^{* *}$ & 1 & \\
\hline (3) Solar altitude $\left({ }^{\circ}\right)$ & .36 & 37.17 & 35040 & $.680^{* *}$ & $.229^{* *}$ & 1 \\
\hline
\end{tabular}

** Correlation is significant at the 0.01 level (2-tailed). Correlation is significant at the 0.05 level (2-tailed).

incident of the direct solar rays. As such, the correlation between solar altitude and direct solar radiation should be positive and strong. In this section, however, we attempt to show the correlation between solar altitude and global horizontal radiation: the sum of global direct radiation and global diffuse radiation. The latter is affected by the presence of clouds and other atmospheric particles. Figure 29 is a graph showing the dispersion of global horizontal radiation in relation to solar altitude. By the result of 2011-2014 hourly data analysis, there was no correlation as shown in Figure 29. This is because there are many numbers of assay value $(N=$ 17,687), which obstructs field of vision. However, through statistical analysis, the coefficient of determination was found to be $R^{2}=0.463$. This means that the independent variable explains $46.3 \%$ of the dependent variable, thus indicating an extremely high correlation.

The results obtained through the analysis of correlations between total solar irradiation in 2011-2014, GHR/EHR, and solar altitude indicate a strong correlation between total solar irradiation and solar altitude to be $R=0.68$, which means being highly correlated. However, the correlation between GHR/EHR and solar altitude is $R=0.229$. This could mean that the relation between total solar irradiation and GHR/EHR is not strong or that there is another variable affecting the relationship of the two variables. There are several reasons why the results presented in this chapter might not have offered accurate explanations to the questions of the subject matter. For instance, it could be due to the effect of other factors that are not considered by the study. As such, determining other factors that are likely to affect solar radiation is of paramount importance. Table 3 shows the analysis of correlation of solar radiation and solar altitude.

3.2.3. Statistical Correlation between Solar Radiation and Sky Cover. In Figure 30, the analysis was carried out by setting up the 0 point global horizontal radiation as discrete missing

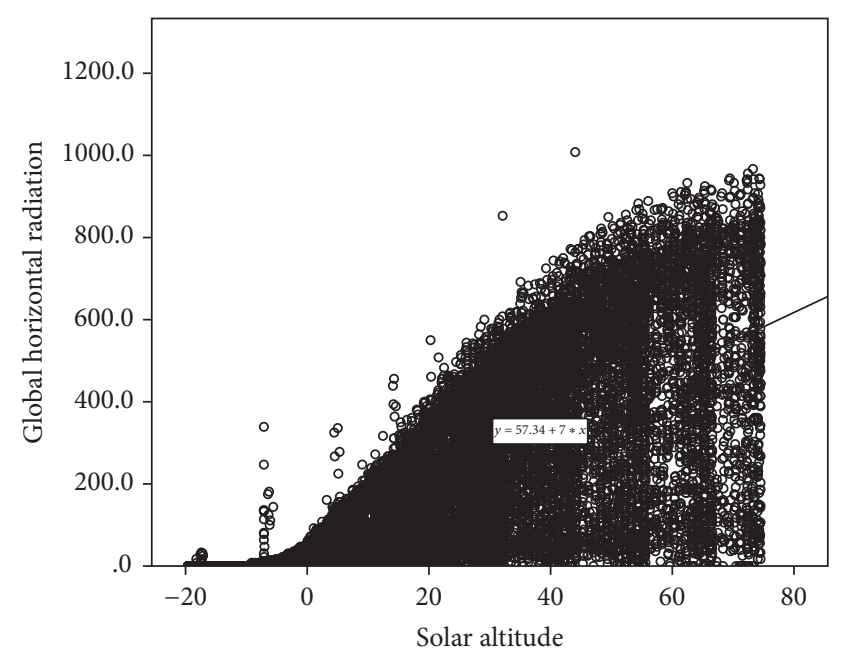

FIGURE 29: Scatter diagram showing the relationship between global horizontal radiation and solar altitude.

data then assayed the relationship between sky cover and solar radiation. The calculated cloud cover (cloudiness) data shows 10-tenths data, which signifies less subdivisions as compared to other data. It also becomes difficult to optically distinguish the relation because the number of data related to dispersion in Figure 30 is greatly large. However, the result value was lower than the predicted value, considering the close relation of sky cover and solar radiation. As such, it can be assumed that there are other factors that affect solar radiation besides clouds.

Figure 30 indicates that the ratio of global horizontal radiation to extraterrestrial horizontal radiation has a negative correlation as the sky cover increases. This happens when discrete missing data of global horizontal radiation is 0 . Notably, the correlation with GHR/EHR was $R=-0.573$ and 
TABLE 4: Correlation of solar radiation and sky cover.

\begin{tabular}{|c|c|c|c|c|c|c|c|c|c|}
\hline \multirow{2}{*}{ Variables } & \multirow{2}{*}{ Mean } & \multirow{2}{*}{ Std. deviation } & \multirow{2}{*}{$N$} & \multicolumn{6}{|c|}{ Pearson correlation } \\
\hline & & & & (1) & (2) & (3) & (4) & (5) & $(6)$ \\
\hline (1) Total sky cover & 4.81 & 3.93 & 35040 & 1 & & & & & \\
\hline (2) Horizontal infrared radiation $\left(\mathrm{Wh} / \mathrm{m}^{2}\right)$ & 638.20 & 318.79 & 35040 & $.928^{* *}$ & 1 & & & & \\
\hline (3) Global horizontal radiation $\left(\mathrm{Wh} / \mathrm{m}^{2}\right)$ & 275.29 & 228.63 & 17692 & $-.319^{* *}$ & $-.225^{* *}$ & 1 & & & \\
\hline (4) Direct normal radiation $\left(\mathrm{Wh} / \mathrm{m}^{2}\right)$ & 101.57 & 192.08 & 35040 & $-.316^{* *}$ & $-.282^{* *}$ & $.727^{* *}$ & 1 & & \\
\hline (5) Diffuse radiation $\left(\mathrm{Wh} / \mathrm{m}^{2}\right)$ & 81.29 & 116.99 & 35040 & $.024^{* *}$ & $.119^{* *}$ & $.810^{* *}$ & $.516^{* *}$ & 1 & \\
\hline (6) GHR/HER (\%) & 38.54 & 20.65 & 17687 & $-.583^{* *}$ & $-.542^{* *}$ & $.807^{* *}$ & $.870^{* *}$ & $.570^{* *}$ & 1 \\
\hline
\end{tabular}

*** Correlation is significant at the 0.01 level (2-tailed). Correlation is significant at the 0.05 level (2-tailed).

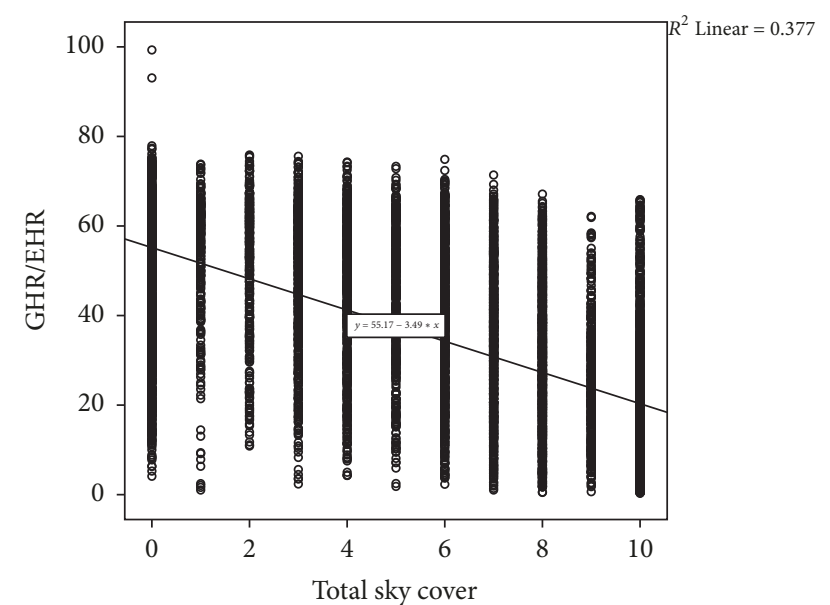

FIGURE 30: Scatter diagram showing the relationship between GHR/EHR and total sky cover.

was $R=-0.319$ with global horizontal radiation, which means that the sky cover with GHR/EHR is more visibly correlated than the one with only global horizontal radiation.

Unlike the results obtained with solar radiation, horizontal infrared radiation and sky cover had a positive correlation of $R=0.928$, which is closer to 1 . This means that sky cover has a large influence on the horizontal infrared radiation. Table 4 shows the analysis of correlation of solar radiation and sky cover.

\subsubsection{Statistical Correlation between Solar Radiation and AOD} (Aerosol Optical Depth). In case of hourly total sky cover values from 0 to 2 in the period 2011-2014, Table 5 shows the correlation of AOD, global horizontal radiation, and GHR/EHR values from July to September.

The reason for considering only 0,1 , and 2 of total sky cover (value) is that the results were only analyzed for the purpose of eliminating factors which could have an effect on attenuation between two variables, and then the results were assayed in clear sky when analyzing correlation between AOD and solar radiation.

Analysis shows that AOD has negative correlations with the majority of the variables related to solar radiation, especially, the correlation between AOD and direct solar radiation which indicated an $R$-value of -0.442 as well as the correlation between AOD and GHR/EHR which indicated an $R$-value of -0.45 . Previously, the correlation coefficient between sky cover and solar radiation was not over 0.5 , which is an indicator of a possible existence of other strong variables.

After a thorough analysis of the obtained data, AOD could also be classified as a strong attenuation factor. As precipitable water is related to the amount of clouds, the correlation between precipitable waters and horizontal infrared radiation is higher than 0.444 . Table 5 shows the analysis of correlation of solar radiation and AOD.

3.2.5. Statistical Correlation between AOD (Aerosol Optical Depth) and Aerosols. Table 6 is the result of the analysis on the correlation between AOD and airborne dust in all sky conditions for four years. The correlation of each unit is over 0.7. The results of $\mathrm{SO}_{2}, \mathrm{NO}_{2}, \mathrm{PM}-10, \mathrm{CO}$, and $\mathrm{O}_{3}$ with $\mathrm{AOD}$ showed no correlation. The absolute value was not higher than 0.1. This is expected due to the influence of AOD on analyzed airborne dust data such as sky cover, humidity, and also outer atmosphere data such as $\mathrm{PM}-10, \mathrm{CO}_{2}$, and $\mathrm{O}_{3}$.

\section{Conclusion}

Descriptive analysis of monthly average and frequency of weather elements was conducted. 35,040 hourly weather datasets belonging to Seoul city for a time period of 2011 to 2014 were utilized for the study. This data was obtained from KMA measured data as well as data calculated by equations, while the data describing the AOD and precipitable water were obtained from the AERONET system. The obtained data is an accurate depiction of Seoul's climatic conditions.

As shown through the obtained results, although extraterrestrial direct radiation is the lowest in summer, dry-bulb temperature is the highest in summer. Also, the horizontal infrared radiation follows a similar tendency to that shown by the dry-bulb temperature.

Theoretically, solar radiation in summer is expected to be higher than that of other seasons. However, the actual calculated value is quite low. This might be due to the attenuation of total sky cover and other atmospheric elements. Nevertheless, this provides further proof that outdoor temperature cannot be merely explained by the solar radiation factor alone.

In the case of AOD, the values for June and July were relatively high and showed a varying tendency to that of aerosols. This is because there is a high amount of precipitable water in the atmosphere, in June, July, and August as it is a rainy season and typhoon season in South Korea. Also, 
TABLE 5: Correlation of solar radiation and AOD (aerosol optical depth).

\begin{tabular}{|c|c|c|c|c|c|c|c|c|c|c|}
\hline \multirow{2}{*}{ Variables } & \multirow{2}{*}{ Mean } & \multirow{2}{*}{ Std. deviation } & \multirow{2}{*}{$N$} & \multicolumn{7}{|c|}{ Pearson correlation } \\
\hline & & & & (1) & (2) & (3) & (4) & $(5)$ & (6) & (7) \\
\hline (1) AOD & .43 & .33 & 104 & 1 & & & & & & \\
\hline (2) Precipitable water $(\mathrm{cm})$ & 2.39 & .86 & 104 & $.405^{* *}$ & 1 & & & & & \\
\hline (3) GHR/HER (\%) & 49.96 & 16.94 & 634 & $-.422^{* *}$ & .094 & 1 & & & & \\
\hline (4) Horizontal infrared radiation $\left(\mathrm{Wh} / \mathrm{m}^{2}\right)$ & 426.59 & 82.04 & 634 & .018 & $.444^{* *}$ & .066 & 1 & & & \\
\hline (5) Global horizontal radiation $\left(\mathrm{Wh} / \mathrm{m}^{2}\right)$ & 357.63 & 260.04 & 634 & $-.271^{* *}$ & $.200^{*}$ & $.845^{* *}$ & $.227^{* *}$ & 1 & & \\
\hline (6) Direct normal radiation $\left(\mathrm{Wh} / \mathrm{m}^{2}\right)$ & 333.69 & 237.60 & 634 & $-.450^{* *}$ & .074 & $.920^{* *}$ & -.007 & $.795^{* *}$ & 1 & \\
\hline (7) Diffuse radiation $\left(\mathrm{Wh} / \mathrm{m}^{2}\right)$ & 159.96 & 107.02 & 634 & -.069 & $.228^{*}$ & $.571^{* *}$ & $.358^{* *}$ & $.807^{* *}$ & $.369^{* *}$ & 1 \\
\hline
\end{tabular}

${ }^{* *}$ Correlation is significant at the 0.01 level (2-tailed). ${ }^{*}$ Correlation is significant at the 0.05 level (2-tailed).

TABLE 6: Correlation of AOD and aerosols.

\begin{tabular}{|c|c|c|c|c|c|c|c|c|c|}
\hline \multirow{2}{*}{ Variables } & \multirow{2}{*}{ Mean } & \multirow{2}{*}{ Std. deviation } & \multirow{2}{*}{$N$} & \multicolumn{6}{|c|}{ Pearson correlation } \\
\hline & & & & (1) & (2) & (3) & (4) & (5) & (6) \\
\hline (1) $\mathrm{SO}_{2}(\mathrm{ppm})$ & 10.32 & 101.02 & 35039 & 1 & & & & & \\
\hline (2) PM-10 $\left(\mu \mathrm{g} / \mathrm{m}^{3}\right)$ & 30.53 & 119.70 & 35039 & $.757^{* *}$ & 1 & & & & \\
\hline (3) $\mathrm{O}_{3}(\mathrm{ppm})$ & 12.04 & 109.10 & 35039 & $.922^{* *}$ & $.698^{* *}$ & 1 & & & \\
\hline (4) $\mathrm{NO}_{2}(\mathrm{ppm})$ & 17.41 & 130.88 & 35039 & $.764^{* *}$ & $.593^{* *}$ & $.705^{* *}$ & 1 & & \\
\hline (5) CO (ppm) & 11.18 & 107.49 & 35039 & $.936^{* *}$ & $.712^{* *}$ & $.865^{* *}$ & $.761^{* *}$ & 1 & \\
\hline (6) $\mathrm{AOD}$ & .65 & .61 & 8138 & .006 & $.076^{* *}$ & .006 & $-.022^{*}$ & .009 & 1 \\
\hline
\end{tabular}

${ }^{* *}$ Correlation is significant at the 0.01 level (2-tailed). ${ }^{*}$ Correlation is significant at the 0.05 level (2-tailed).

solar radiation has an inverse relationship with sky cover, precipitable water, and AOD. According to the analysis of each relation, global horizontal radiation was the lowest in summer.

In results of statistical correlation, the relationship values between variables of weather data were analyzed and converted into correlation coefficient. The relationship between outdoor temperature and solar radiation is usually assumed to be almost of a linear nature. However, according to the calculated values, the interdependence of the two variables is not that directly proportional. This is because elements such as AOD, sky cover, and time lag were not considered in the first instance.

In addition, the higher the solar altitude, the higher the levels of solar radiation; however, a correlation between these 2 variables indicates a relatively low $R$-value. The results are then proof of the existence of other outer interventions caused by weather conditions.

The $R$-value obtained from matching global horizontal radiation to GHR/EHR was shown to be quite low. On the other hand, the $R$-value shown by the relationship between direct radiation and GHR/EHR is too high. Evidently, according to the results, sky conditions are a contributing factor to the relationship between GHR/EHR and direct radiation.

As such, even though matching solar radiation and AOD produce a negative correlation coefficient, each of the variables was not able to individually explain the levels of solar radiation.

\section{Conflicts of Interest}

The authors declare no conflicts of interest as far as this manuscript is concerned.

\section{References}

[1] L. DR International, L. D \& R International, 2010 Buildings Energy Data Book. U.S. Department of Energy, Mar. 2010, tables 1.1.3, 3.1.1. http://buildingsdatabook.eren.doe.gov/ docs\%5CDataBooks\%5C2010BEDB.pdf.

[2] Markus, Thomas Andrew, and Edwin N. Morris. Buildings, climate, and energy. Pitman Pub., 1980.

[3] J. A. Duffie and W. A. Beckman, Solar Engineering of Thermal Processes, vol. 3, Wiley, New York, NY, USA, 1980.

[4] E. Aguado and J. E. Burt, Understanding Weather and Climate, Pearson Prentice Hall, Upper Saddle River, NJ, USA, 2007.

[5] A. Tsangrassoulis, Short-Wave Radiation, James and James Ltd., London, UK, 2001.

[6] T. B. McKee and S. K. Cox, "Scattering of visible radiation by finite clouds," Journal of the Atmospheric Sciences, vol. 31, no. 7, pp. 1885-1892, 1974.

[7] D. B. Crawley et al., "Energy plus: energy simulation program," ASHRAE Journal, pp. 49-56, 2000.

[8] Handbook-Fundamentals, A. S. H. R. A. E. "American society of heating, refrigerating and air-conditioning engineers." Inc., NE Atlanta, GA 30329 (2009).

[9] I. L. Alboteanu, C. A. Bulucea, and S. Degeratu, "Estimating solar irradiation absorbed by photovoltaic panels with low concentration located in Craiova, Romania," Sustainability, vol. 7, no. 3, pp. 2644-2661, 2015.

[10] D. Thevenard and C. A. Gueymard, "Updating the ASHRAE climatic data for design and standards," in Proceedings of the 2010 ASHRAE Annual Conference, pp. 444-458, June 2009.

[11] The Globe Program (2002). Aerosols Protocol. http://globe.gov/ sda/tg00/aerosol.pdf.

[12] D. Thevenard and C. A. Gueymard, "Updating the ASHRAE climatic data for design and standards," in Proceedings of the 2010 ASHRAE Annual Conference, pp. 444-458, June 2010. 
[13] NASA EARTH OBSERVATORY, http://earthobservatory.nasa gov.

[14] Annual report of air quality in Korea in 2014 from Ministry of Environment and National Institute of Environmental Research. http://www.me.go.kr/home/web/main.do. 

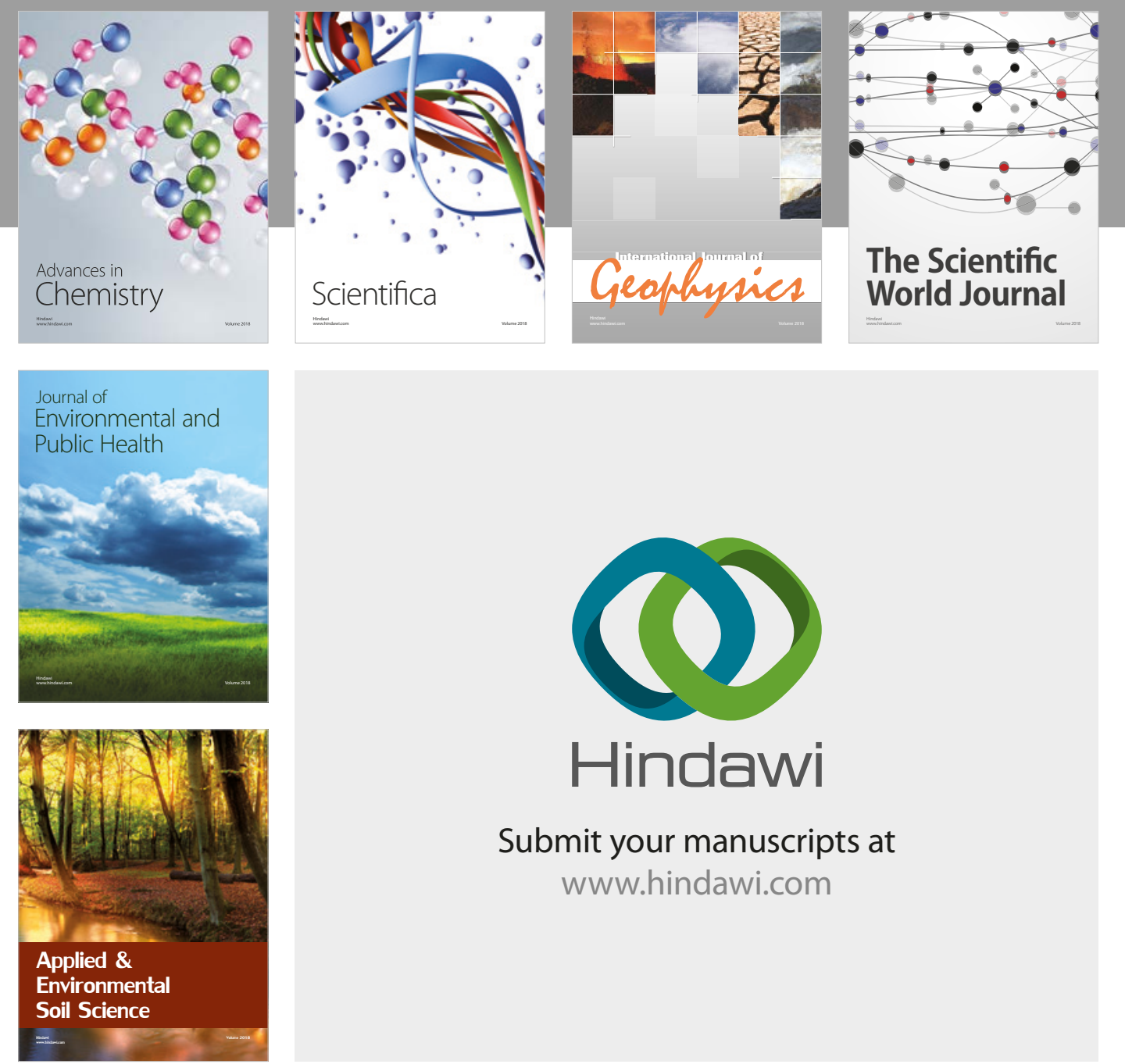

The Scientific

\section{World Journal}
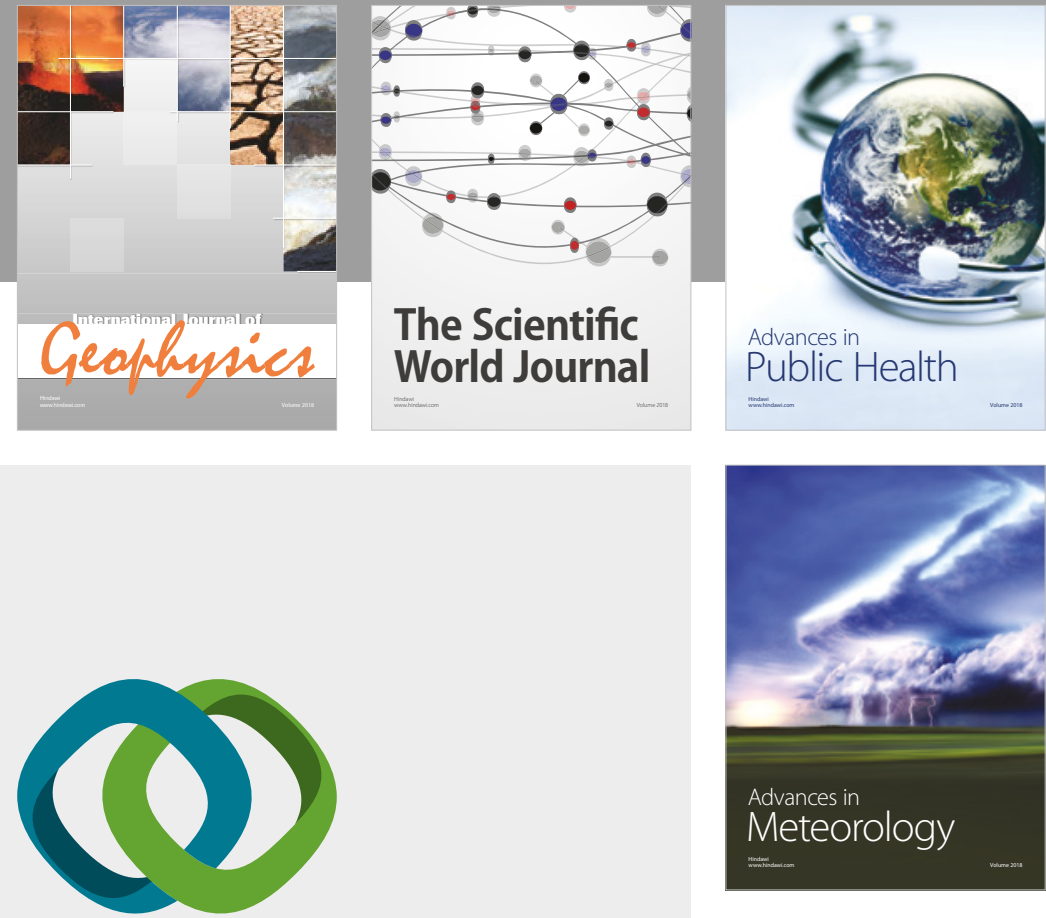

Advan

Public Health

\section{Hindawi}

Submit your manuscripts at

www.hindawi.com
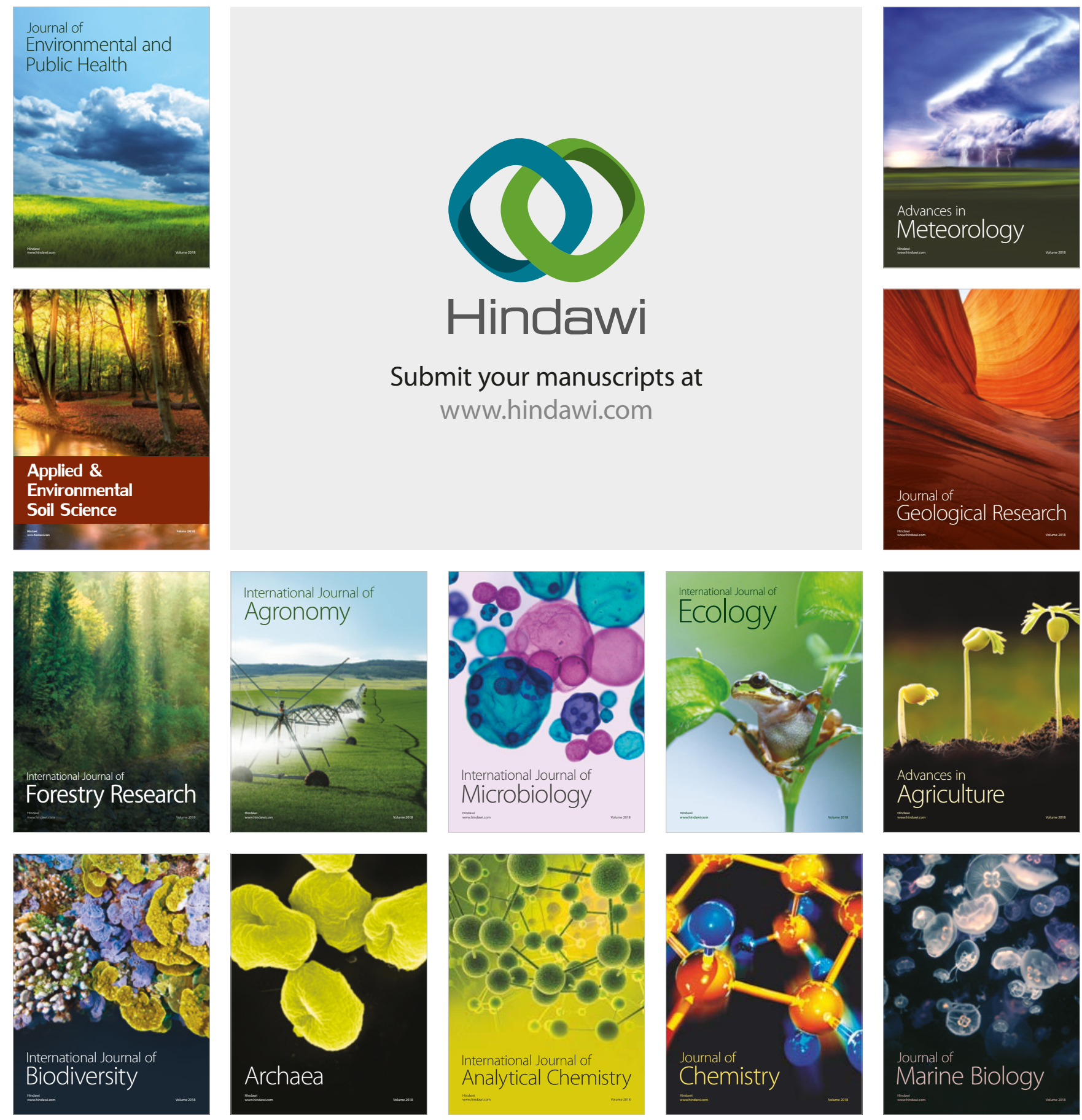